Portland State University

PDXScholar

2-12-1996

\title{
Temperament and Language Development in First Grade Children
}

Loretta Marcia Kellogg

Portland State University

Follow this and additional works at: https://pdxscholar.library.pdx.edu/open_access_etds

Part of the Speech and Rhetorical Studies Commons

Let us know how access to this document benefits you.

\section{Recommended Citation}

Kellogg, Loretta Marcia, "Temperament and Language Development in First Grade Children" (1996). Dissertations and Theses. Paper 5283.

https://doi.org/10.15760/etd.7156

This Thesis is brought to you for free and open access. It has been accepted for inclusion in Dissertations and Theses by an authorized administrator of PDXScholar. Please contact us if we can make this document more accessible: pdxscholar@pdx.edu. 
THESIS APPROVAL

The abstract and thesis of Loretta Marcia Kellogg for the Master of Science in Speech Communication: Speech and Hearing Science were presented February 12, 1996 and accepted by the thesis committee and the department.

COMMITTEE APPROVALS:

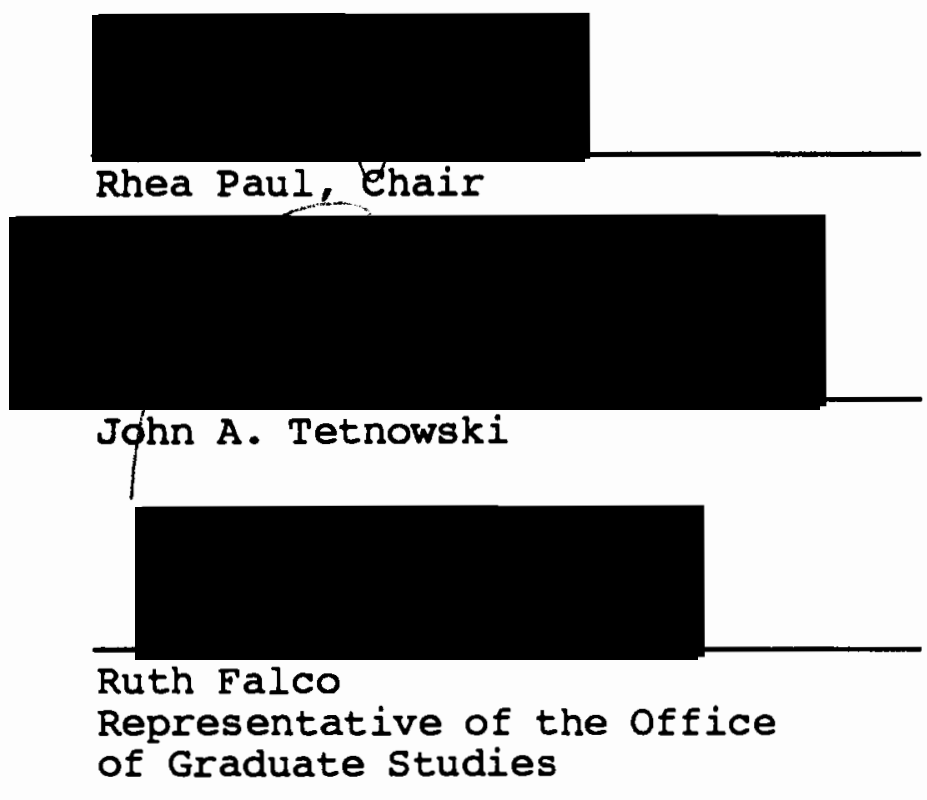

DEPARTMENT APPROVAL:

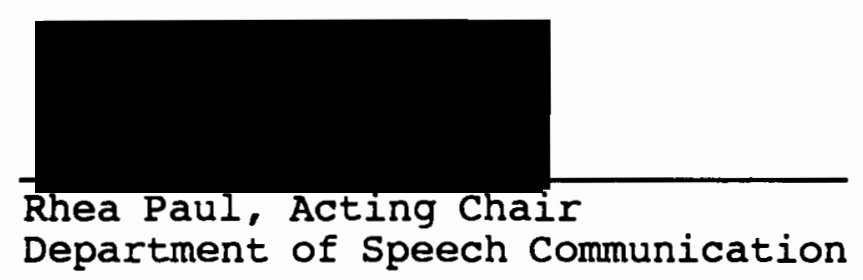

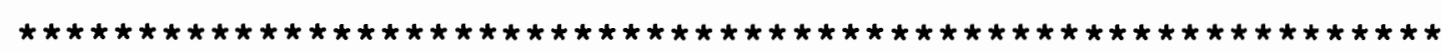

ACCEPTED FOR PORTLAND STATE UNIVERSITY BY THE LIBRARY

by

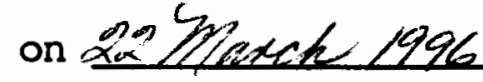




\section{ABSTRACT}

An abstract of the thesis of Loretta Marcia Kellogg for the Master of Science in Speech Communication: Speech and Hearing Science presented February 12, 1996.

Title: Temperament and Language Development in First Grade children.

Many young children develop language over a broad range of ages yet present as having normal language development. When language development lags behind what is considered a normal time line, it is important to consider the various factors that may contribute to the delay in development.

The purpose of the current study was to examine various aspects of temperament among three groups of children with varying language histories. The specific question to be answered was, do significant differences occur on parent and clinician questionnaires of temperament among three groups of first grade children demonstrating varying levels of language development: those with normal language (NL), those with a history of expressive language delay (HELD), and those with chronic expressive language delay (ELD)?

Subjects for this study included 23 subjects in the NL 
group, 22 subjects in the HELD group, and 6 subjects in the ELD group. The groups were compared utilizing the Temperament Assessment Battery for Children (TABC) on six variables of temperament on Parent Forms and five variables of temperament on Clinician Forms. The data were analyzed to see if significant differences existed among the language diagnostic groups. On the Parent Forms, a trend towards low approach/withdrawal characteristics was observed between the NL and ELD groups. On the Clinician Forms, a significant difference was observed on the variable, approach/withdrawal, between the NL group and HELD group. Both parametric and non-parametric analyses were in agreement on this finding. The suggestion that low approach/withdrawal tendencies exist within late talking children may be the long term result of interaction between expressive language delayed children and the communication environment. These results must be viewed tentatively because the sample groups were of unequal numbers. If all diagnostic groups had been of equivalent size, the results may have been yielded stronger significance. 
TEMPERAMENT AND LANGUAGE DEVELOPMENT

IN

FIRST GRADE CHILDREN

by

LORETTA MARCIA KELLOGG

A thesis submitted in partial fulfillment

of the requirements for the degree of

\author{
MASTER OF SCIENCE \\ in \\ SPEECH COMMUNICATION: \\ SPEECH AND HEARING SCIENCE
}

Portland State University

1996 
TABLE OF CONTENTS

PAGE

LIST OF TABLES . . . . . . . . . . . . . . viii

\section{CHAPTER}

I INTRODUCTION . . . . . . . . . 1

Statement of Purpose. . . . . . . 2

Definition of Terms ........ 3

II REVIEW OF THE LITERATURE . . . . . . . 6

Traits of Temperament ....... 7

Behavior and Temperament. . . . . 12

Behavior Disorders and

Language Disorders . . . . . 12

Temperament Characteristics of

Children At-Risk for

Development Disorders. . . . 16

The Development of Temperament

Rating Scales. . . . . . . 19

Summary . . . . . . . . . . 23

III METHODS AND PROCEDURES . . . . . . . . 26

Subjects. ........... 26

Recruitment

Diagnostic Group Assignment: Age 2

Follow-Up Assessment: First Grade

Diagnostic Groups: First Grade

Instrumentation . . . . . . 30

Procedures. . . . . . . . 34 
Data Analysis. . . . . . . . . . 35

IV RESULTS AND DISCUSSION. . . . . . . . . 37

Results. . . . . . . . . . 37

Discussion . . . . . . . . . . 40

V SUMMARY AND IMPLICATIONS. . . . . . . . 46

Summary. . . . . . . . . . . 46

Implications . . . . . . . . . . 48

Research

clinical

REFERENCES • . . . . . . . . . . . . . . . . 51 APPENDIXES

A hUMAN SUBJECT APPROVAL . . . . . . . . . . 55

B PARENT PERMISSION FORM . . . . . . . . 57

C QUESTIONNAIRE FOR PARENTS OF CHILDREN

15-30 MONTHS OLD . . . . . . . . . . 59

D LANGUAGE DEVELOPMENT SURVEY. . . . . . . . 61

E DEVELOPMENTAL SENTENCE SCORE:

SCORING CRITERIA . . . . . . . . . . . 63

F DEVELOPMENTAL SENTENCE SCORE:

NORMS. . . . . . . . . . . . . . . 66

G TABC: PARENT RATING FORM. . . . . . . . . 68

H TABC: PARENT SCORING SHEET. . . . . . . 71

I TABC: CLINICIAN RATING FORM/SCORING SHEET • . 73

J TABC RESULTS: RAW DATA. . . . . . . . 77

Parent Forms

Normal Language . . . . . . . . . 78

History of Expressive Language Delay. • 79

Expressive Language Delay . . . . . 80 
Clinician Forms

Normal Language . . . . . . . . . . 81

History of Expressive Language Delay. • 82

Expressive Language Delay . . . . . . 83

K TABC RESULTS: T-SCORES. . . . . . . . . 84

Parent Forms

Normal Language . . . . . . . . . 85

History of Expressive Language Delay. . 86

Expressive Language Delay . . . . . 87

Clinician Forms

Normal Language . . . . . . . . . 88

History of Expressive Language Delay. . 89

Expressive Language Delay . . . . . . 90 
I Four Lists of Temperament Variables ... . 10

II Group Description at Intake . . . . . . . 28

III Group Description at First Grade. . . . . . 29

IV Means and Standard Deviations of

Temperament Variables: Parent Forms . . 38

$\mathrm{V}$ Means and Standard Deviations of

Temperament Variables: Clinician Forms. 39

VI ANOVA, Tukey Test, and Kruskal-Wallis

Test Results based on Parent Forms. . . 41

VII ANOVA, Tukey Test, and Kruskal-Wallis

Test Results based on Clinician Forms . 42 
CHAPTER I

INTRODUCTION

As knowledge about language development and disorder grows, attempts are being made to identify variables that may predict normal or disordered development in young children with early delays. Current research continues to attempt to profile children with language disorders at various age levels in the hopes of identifying specific factors that may predict which children are at risk for chronic language disabilities. One of the variables to be considered is personality, or behavioral characteristics, also described as temperament. Does temperament affect outcome of early language delay?

The temperamental style of a child has the potential for significantly impacting his/her social interactions and, as a result, the types of language stimulation provided. If a child cries infrequently, smiles often, and adapts easily to new situations and people, there is a greater likelihood that people in the child's environment will engage in positive verbal exchanges with the child. Conversely, if the child cries often and reacts with withdrawal and fearfulness to new situations and people, parents and caretakers may be less inclined to provide positive language models. Thus, specific temperamental profiles may either enhance or hinder language development. 
STATEMENT OF PURPOSE

The purpose of this study is to examine and compare parent and clinician reports of temperament characteristics of three groups of first grade children with varying language histories: those with normal language (NL), those considered late talkers (LT) as toddlers, but have achieved skills within the normal range by first grade (history of expressive language delay or HELD), and those who were LT as toddlers and continue to exhibit expressive language delay (ELD) at first grade.

Hypothesis

It is hypothesized that significant differences will occur on parent and clinician questionnaires of temperament among three groups of first grade children who demonstrate varying levels of language development; those with NL, those with HELD, and those with ELD.

\section{Null Hypothesis}

First grade children demonstrating varying levels of language development; those with NL, those with HELD, and those with ELD, will exhibit no significant differences on parent and clinician questionnaires of temperament. 
DEFINITION OF TERMS

The following operational definitions were used for this study. Several of the definitions were taken directly from the Temperament Assessment Battery for Children (TABC) manual (Martin, 1988) which was the instrument used for this study.

Activity: The TABC manual (Martin, 1988) defines this variable as "the tendency to engage in gross motor movement, particularly vigorous, fast movement" (p. 18).

Adaptability: The TABC manual (Martin, 1988) defines this variable as "the ease and speed with which a child adjusts to new social situations" (p.18).

Approach/Withdrawal: The TABC manual (Martin, 1988) defines this variable as "the tendency to approach versus withdraw from new social situations" (p. 19).

Difficult Child: Thomas and chess (1982) define the difficult child as one who is "characterized by irregularity in biological functions, a predominance of negative (withdrawal) responses to new stimuli, slowness in adapting to changes in environment, a relatively high frequency of expression of negative mood, and a predominance of high intensity in mood expression" (p. 4).

Distractibility: The TABC manual (Martin, 1988) defines this variable as "the ease with which the child's attention can be disrupted by environmental stimuli, particularly low level stimuli" (p. 19).

Ease-of-Manaqment Through Distraction: The TABC manual (Martin, 1988) defines this variable as "the ease with which 
a child can be distracted from inappropriate behavior toward appropriate behavior by an adult caretaker" (p.20).

Easy Child: Thomas and Chess (1977) define the easy child as one who demonstrates regularity, positive approach responses to new stimuli, high adaptability to change and mild or moderately intense mood which is mostly positive.

Emotional Intensity: The TABC manual (Martin, 1988) defines this variable as "the tendency to express emotions, particularly negative emotions (e.g., anger, frustration), with vigor" (p. 19).

Expressive Lanquage Delay (ELD) Subjects: The subjects were considered to be in the ELD group if they had slow expressive language development at age 20-34 months, using the Language Developmental Survey (LDS) (Rescorla, 1989) criterion, and also received a score of less than 6.35 on the Development Sentence Scoring (Lee, 1974) at first grade.

History of Expressive Lanquage Delay (HELD) Subjects: Children were identified as having a history of expressive language delay if they used less than 50 words on the Language Development Survey (Rescorla, 1989) and no two word combinations by the age of 20-34 months.

Late Talkers (LT) Subjects: The subjects were considered to be in the IT group if they were identified as late talkers at age 20-34 months by use of less than 50 words and no use of two word combinations using the LDS (Rescorla, 1989 ).

Normal Lanquage (NL) Subjects: The subjects were considered to have normal language if they used more than 50 
different words at age 20-34 months as reported by the parents on the LDS and also scored 6.35 or above on the DSS (Lee, 1974) at first grade.

Persistence: The TABC manual defines persistence as “attention span and the tendency to stick with difficult learning or performance situations" (Martin, 1988, p. 20).

Rhythmicity: Thomas and Chess (1977) define rhythmicity as "the predictability and/or unpredictability in time of any function. It can be analyzed in relation to the sleep-wake cycle, hunger, feeding pattern and elimination schedule" (p. 21).

Slow-to-Warm-up Child: Thomas and chess (1977) define the slow-to-warm-up-child as one who demonstrates a combination of negative responses of mild intensity to new stimuli with slow adaptability after repeated contact.

Temperament: Temperament is defined by Webster's dictionary (1989) as "the characteristic physiological and emotional state of an individual, which tends to condition his responses to the various situations of life" (p. 1017).

Temperament Profile: A temperament profile is the result of scores on a temperament rating scale which may place a child in a category of Easy Child, Slow-to-Warm-up Child, or Difficult Child.

Trait: A trait is defined by Webster's dictionary (1989) as "a distinguishing characteristic, quality or feature" (p. 1047). 
CHAPTER II

\section{REVIEW OF THE LITERATURE}

The explanation of exactly what determines or predicts a child's course of development has been under discussion for hundreds of years (Thomas \& Chess, 1977). One of the variables under consideration is temperament and the role it plays in the overall development of an individual. More specifically, what role does temperament play in the development of language?

In the 1950s, there was a strong trend toward environmentalism as the most influential factor in shaping young lives (Thomas \& Chess, 1977). It has been well documented that environment does indeed play a strong role in development (Bradley, 1993). However, some researchers believe the environment plays a very small role in approximately the first year, to year and a half of life (Thomas \& Chess, 1977). Prior to the second year of life there are other factors involved in development which have come under investigation. Inherent individual differences have been observed by pediatricians in newborn infants that do not all respond the same way to the same environmental circumstances (Thomas \& Chess, 1977). Some of those individual differences have come to be known as temperament (Thomas \& Chess, 1977; Buss \& Plomin, 1984; Bates, 1989). 
TRAITS OF TEMPERAMENT

Temperament is not easily defined. It is generally regarded as a subclass of personality (Buss, 1991; Bates, 1989; Martin, 1988). However, Martin, (1988) suggests that temperament may be developmentally a more fundamental concept than personality because it focuses on behavioral differences seen at birth, thereby preceding personality which develops over time and experience. The preliminary features that lay the foundation for defining temperament are its apparent biological origin based on its early appearance in life and its stability over situations and time (Buss, 1991; Bates, 1989; Martin, 1988).

In the mid-1950s, Thomas \& Chess conducted a study to examine the importance of constitutional differences within individual children, which when combined with environmental influences, seemed to explain and/or predict differences in development. These constitutional differences have been identified as temperament (Thomas \& Chess, 1977).

According to Thomas \& Chess (1977), temperament is viewed as the how of behavior, whereas ability is concerned with what and how well a behavior is manifested, and motivation accounts for why an individual is doing what he/she is doing. The notion that temperament is concerned with the how of behavior is generally accepted by those who study temperament (Martin, 1988; Thomas \& Chess, 1977, Fullard et. al., 1984). In this light, temperament is described as behavioral style (Fullard et. al., 1984). 
Behavioral style is how an individual responds to a particular stimulus.

Thomas and Chess (1977) felt it was very important to look at temperament as the interaction between the child's inherent abilities and motives and external environmental stresses and opportunities. They felt that the perception of a child as "easy" or "difficult", was based on the consonance or dissonance of the child's temperament interacting with his/her situational environment. If a child's temperament matches or is in consonance with his/her environmental demands, he/she is perceived as an easy child. Conversely, if the environmental interaction overwhelms the child's abilities to respond in a socially acceptable manner, he/she may be perceived as a difficult child. Hence, the temperament of the child is in dissonance or discord with the environment. Thomas and Chess (1977) theorize that perception of temperament is based on goodness of fit between the child's abilities and environmental demands.

The New York Longitudinal Study (NYLS) (Thomas \& Chess, 1977) was designed to identify very specific aspects of temperament. This study followed a group of $141 \mathrm{child}$ ren from 1956 to 1961. The data gathered for this study was obtained from quantitative and qualitative information about a child's behavior in various situations as obtained by parent interview. Follow-up data was provided by independent observers in the home and, in later years, by teachers. The information derived from this study identified the following nine aspects of temperament (Thomas \& Chess, 1977, p. 21-22): 
1. Activity level

2. Rhythmicity (regularity)

3. Approach or withdrawal

4. Adaptability

5. Threshold of Responsiveness

6. Intensity of Reaction

7. Quality of Mood

8. Distractibility

9. Attention Span and Persistence

The results of this study yielded three distinct temperamental styles in children. The "Easy Child" is characterized by regularity, positive approach responses to new stimuli, high adaptability to change and mild or moderately intense mood which is mostly positive.

The second category of temperamental style is the "Difficult Child" characterized by irregularity in biological functions, negative withdrawal responses to new stimuli, nonadaptability or slow adaptability to change, and intense mood expressions which are frequently negative.

The third category identified by this study describes the "Slow-To-Warm-Up Child". This temperamental style is marked by a combination of negative responses of mild intensity to new stimuli with slow adaptability after repeated contact.

As Martin, (1988) illustrates, there is agreement amongst researchers as to the general domain of temperament; however, there is disagreement as to how many temperamental variables exist. An example of the different variables 
proposed by four researcher-theorists is presented in Table I.

TABLE I

FOUR LISTS OF TEMPERAMENT VARIABLES

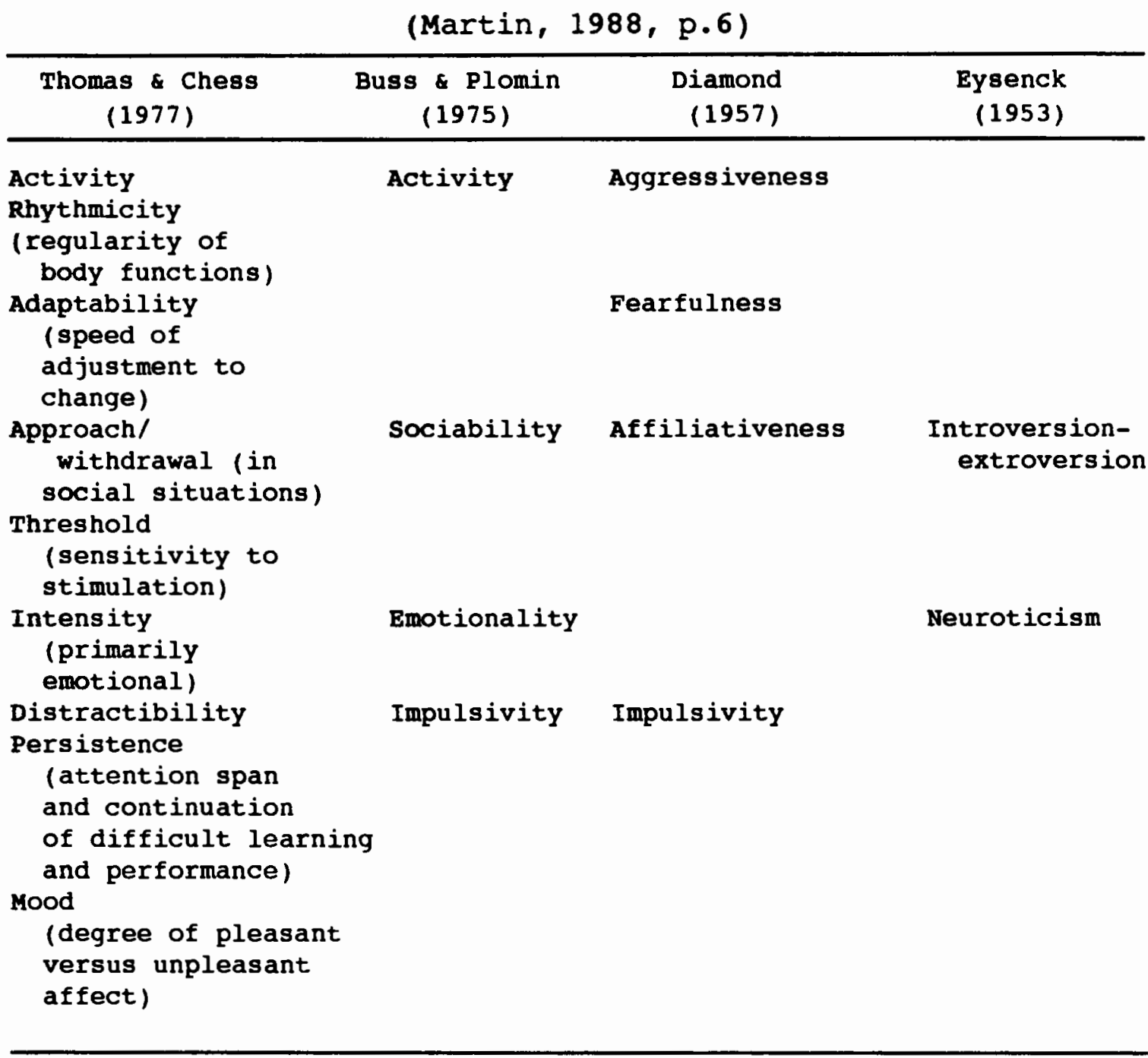

This appears to be a difference in perspective, but upon closer examination, many of the variables listed by the different researchers can be correlated to the categories listed by the other researchers. Despite having a different number of variables, the researchers in this field are 
essentially in agreement with regard to the general constructs of temperament. These are as follows (Martin, 1988 , p. 3-4):

1. Temperament is an individual difference concept of the trait variety.

2. It is assumed that temperamental traits have some trans-situational and temporal stability, although it is recognized that environments alter significantly the manifestation of that trait.

3. Temperament is thought to be of genetic or constitutional origin.

4. Temperament refers to the style of expression of a behavior or the "how" of behavior rather than to the "what" or the "why."

5. Temperament is a manifestation of reactive and self-regulative processes. In this context, reactivity refers to the "excitability, responsivity, or arousability of the behavioral and physiological systems of the organism (Rothbart \& Derryberry, 1981.)" Self-regulation refers to attempts to control environmental stimulation in order to keep it within a comfortable range.

How important is it to examine the temperament of children who are at risk for developmental delays? According 
to Sparks, (1989) assessment of temperament in the at-risk population may be critical. Through understanding of a child's temperament, it may be possible to modify care-giver behavior to create an environment that is more in consonance with the child, thereby creating the most optimal conditions for development.

\section{BEHAVIOR AND TEMPERAMENT}

From birth, temperamental characteristics are manifested through behavior. Our descriptions of temperament are based on an individual's behavior relative to the environment (Thomas \& Chess, 1977). As an individual grows and matures, behavior becomes the defining element of temperament.

\section{BEHAVIOR DISORDERS AND LANGUAGE DISORDERS}

Behavioral issues as they relate to speech and language disorders have been commented on in the literature since 1937 when orton (1937) observed that as children with language handicaps grow older, behavioral problems become overlaid and intertwined and separating the two is very difficult. Orton's observations have been followed up by many subsequent studies. These studies have made attempts to more clearly identify what types of behavioral disorders coexist with what types of communication disorders and if there is a causal relationship.

Baker, Cantwell, and Mattison (1980) examined behavioral 
disorders in children with pure speech problems as compared to children with speech and language disorders. More behavioral disturbances were reported for children with speech and language disorders than with pure speech disorders. The most significant behavior reported was hyperactivity. This study did not include a comparison of children with normal language development. This study also did not assess temperament, however, it may be possible to make inferences based on the report of "hyperactivity" in terms of that single temperamental trait. The significance of this study is that children with speech and language disorders often exhibit behavioral abnormalities and this should be taken into account when planning intervention. Some people believe that behavior or temperamental traits, such as shyness, limited attention span, and stubbornness, interfere with language development (Hargrove, 1984 ) when, in fact, the language disorder may be implicated in causing the behavioral disorder (Baker \& Cantwell, 1982). If a child does not process the language used in verbal directions, he/she may behave in an inappropriate fashion and receive negative consequences. This pattern may lead to a shyness or reluctance to engage in communication for fear of future negative consequences, thus promoting negative temperamental or behavioral characteristics. At this point in time, the prior scenario is purely speculative. Research in the areas of temperament and language development may reveal if, and how, these two areas of development interrelate. There is growing evidence of the inter relatedness of 
behavior disorders and language disorders. Among children with behavioral or psychiatric disorders, the prevalence of language disorders varies from 248 in an upper-middle class private psychiatric practice (Chess \& Rosenberg, 1974) to 508 in a lower class child-inpatient population (Gualtieri et al., 1983). It's interesting to note that the percentages are very similar in the reverse situation. Of children with language disorders, approximately 508 can be diagnosed as having a psychiatric disorder (Beitchman, Nair, Clegg, \& Patel, 1986; Cantwell \& Baker 1987; Richman, Stevenson, \& Graham, 1975). These studies provide evidence to support the relationship between behavior disorders and language disorders. This information is important for parents, speech-language pathologists, teachers, and mental health professionals to coordinate intervention that addresses all of a child's needs (Giddan, 1991).

The first study to report on language and behavior in the preschool child was done by Stevenson and Richman (1978). They found 148 of their random sample exhibited behavioral problems. In the language delayed population, 598 of the children exhibited behavioral problems. This appears to be a significant finding but the relationship between behavioral problems and language delay cannot be determined because the study does not screen out children with hearing loss, general mental retardation, or factors such as social deprivation (Tallal, Dukette, Curtiss, 1989).

Tallal, Dukette, and Curtiss (1989) discuss the difficulty in comparing and integrating findings across 
studies due to the confusion of terms and definitions. This author agrees. There is little consistency across studies to identify language disorder, language delay, and language impairment. There are also considerable differences in the definition of behavioral disorders and in what attributes are examined in the different behavioral rating scales. These factors are only a few which contribute to the complexity of doing human communication disorder research.

As a result of the problems identified in current research, Tallal, Dukette, and Curtiss (1989) prepared a study of the behavioral profile of language impaired 4-yearold children with an attempt to control for as many variables as could be identified. Results of this study supported previous research by finding increased behavioral disturbance in children with developmental language disorders. This study also draws a correlation between language disorders and behavior disorders, and neurodevelopmental (attention, perception, motor) delay.

As part of a longitudinal study, Paul (1990) compared behavioral traits of children with slow expressive language development at the age of two to a control group. Her findings support the previously cited studies which found a significant percentage of behavioral disorders occurring within the language impaired population. This information can prove useful in consulting with parents and day care providers in suggesting strategies for behavior management and support for continued language stimulation within the home setting. 
A portion of the children identified as SELD at age two improved to within the normal range of language development by age four but 578 continued to show expressive deficits (Paul \& Bauersmith, 1991). If this trend continues, more children will move within the normal range of language development but some will not. One of the purposes in pursuing studies about behavior disorders in relationship to language disorders is an attempt to identify predictive variables (Paul, 1991). By comparing temperamental traits among children with normal language development and those with SELD over a continuum of time, a significant correlation may or may not be identified.

\section{TEMPERAMENTAL CHARACTERISTICS OF CHILDREN AT-RISK FOR DEVELOPMENT DISORDERS}

What role do temperamental characteristics play in the profile of developmentally delayed children? Mehregany (1991), conducted a study of children with psychiatric disorders to examine the relationship of behavior and temperament in this population. Mehregany hypothesized that there would be a high correlation between "difficult child" temperamental characteristics and identification of behavioral disorder. Mehregany found that only one of the "difficult child" characteristics, that of low rhythmicity, distinguished children with behavior disorders. Other temperamental characteristics which correlated with identification of behavioral disorder were high 
distractibility and high activity level. Mehregany suggests that the temperamental characteristics which correlate highly with behavior disorders may identify children at risk for psychopathology.

A study by Maziade et al. (1990) examined the status of adolescents who had extreme temperament at age 7. This study suggests that extremely difficult temperament at age 7 is associated with clinical behavioral disorders in adolescence. However, family behavior control when considered with the temperament of the child was a better predictor of adolescent behavior than temperament alone. This supports the influence of the environment in shaping behavior.

Limited research has been done in the area of children with developmental delays according to a literature review by Goldberg and Marcovitch (1989). The research that has been done has been inconclusive because it has attempted to compare temperamental characteristics of developmentally delayed children with data obtained from the normal population. This may lead to some inappropriate conclusions. For example, in a study by Marcovitch et al. (1987), a group of developmentally delayed preschoolers (Down syndrome, neurological problems, unexplained delays) were rated as easier than the normative sample on the Toddler Temperament Survey (Fullard et al., 1984). However, the mothers' impressions showed they perceived their children to be more difficult than the ratings indicated. In the case of Down syndrome, this perception of "difficult" may be related to the temperamental characteristic of persistence. Children 
with Down syndrome were rated as less persistent than normally developing children. Normal children with low persistence are not typically perceived as "difficult" but in the case of Down syndrome, mothers may view this characteristic as "difficult". This creates somewhat of a dilemma in applying temperamental rating scales to the developmentally delayed population when the rating scales have been normed on typical children.

Despite being identified as having "difficult" temperaments as infants, older children with Down syndrome are rated as temperamentally easier when compared to normally developing peers (Goldberg \& Marcovitch, 1989). This shift toward easier temperament as children mature has also been reported in normally developing children (McDevitt \& Carey, 1978). It would appear that a child's temperament may adapt to the surrounding environment, or, the environment (parents and caregivers) may modify to meet the temperamental style of the child thereby creating a "goodness of fit" between the child and the environment.

In research done by Sameroff, (1974) it was noted that children who received a Difficult Child temperament score on the Carey questionnaire at four months of age showed a highly significant correlation with the Bayley I.Q. score at 30 months of age. This correlation was more significant than comparing Bayley scores at four months and at 30 months. The results of this one study might lead us to rely more heavily on ratings of temperament as predictive of future cognitive ability rather than early cognitive assessments. Further 
research in this area needs to be done to support these findings.

In a study conducted by Heffernan et. al. (1982) no significant difference in temperament was found in a group of neurologically impaired children as compared to normal children. Heffernan et. al. found no confirming reports on specific temperament characteristics associated with specific handicapping conditions at the time of their study. This may be due to the fact that there is no correlation between temperament and developmental handicaps or it may be that research to date has not identified the relationship. The present study hopes to add information to the literature regarding this possible relationship.

Slomkowski et al, (1992) looked specifically at the relationship between temperament and language from toddlerhood to middle childhood. To assess temperament the Infant Behavior Record (IBR) (Bayley, 1969) was administered at the age of 2 . The results were compared to language testing at age 2 , age 3 , and age 7 . Results demonstrated a significant positive correlation between the temperamental construct of affect-extraversion at age 2 and language measures at age 7 . This positive correlation should focus our attention on the role of the child as an active participant in learning language.

THE DEVELOPMENT OF TEMPERAMENTAL RATING SCALES The New York Longitudinal Study (NYLS) (Thomas \& Chess, 
1977) had a major impact on the development of temperamental rating scales as a measure of temperament by establishing a normative database for comparison. Carey, (1970) developed the Infant Temperament Questionnaire as a means of establishing a temperament profile for his infant patients. He constructed a parental rating system to measure each of the nine dimensions of temperament as identified by the NYLS.

Carey was also involved with his colleagues in developing additional parental rating scales. The Toddler Temperament Scale (Fullard, McDevitt, \& Carey, 1984) was developed for 1- to 3-year-olds, and the Behavioral style Questionnaire (McDevitt \& Carey, 1978) was developed for 3to 7-year-olds.

In 1975, Buss \& Plomin identified four aspects of temperament. These aspects were emotionality, activity, sociability, and impulsivity (EASI). Through ongoing research, they dropped impulsivity as an identifying feature in 1984. Through development of the EAS (emotionality, activity, sociability) Theory of Temperament, Buss \& Plomin created the EAS Temperament Survey for Children. This rating scale has different forms for parental ratings and teacher ratings. Survey items were based on data accumulated from the NYLS. Early reports of psychometric properties were related to the earlier version of the EASI and not the current EAS. This instrument reports limited information on its psychometric properties prior to 1994 (Boer \& Westenberg, $1994)$. 
Martin, (1988) has made an attempt to draw the varying elements described as temperament into a more unified focus through his development of the Temperament Assessment Battery for Children. In developing this instrument, Martin has combined the variables identified by earlier researchers to come up with the following six temperamental variables: Activity, Adaptability, Approach/Withdrawal, Emotional Intensity, Ease-of-Management-Through-Distraction (EMTD) or Distractibility, and Persistence. Rating is done on a seven point rating scale. By observing and rating children on these different variables, an understanding of an individual child's temperamental style may be gained.

A few problems have been identified with regard to using parental ratings as the sole measure for assessment of temperament. First, there is the problem of rater bias (Emde et. al., 1992). In earlier attempts to develop valid measures of temperament, parents were used as raters because of their familiarity with the child and because they are a natural part of a child's environment (Martin, 1988). This may yield results of limited value because parent's are emotionally involved with their subject, have their own point of view, and have their own normative frame of reference (Martin, 1988). These results may be somewhat subjective and difficult to duplicate by another rater. Parents are confined by their own history and perspective. Although the parental rating scale may have limitations when considered on its own, it is an extremely valuable piece of information when combined with other professionals' observations 
(Diamond, 1993).

A second problem associated with a single rater of temperament, whether from a parental rating or other rater, is that the rater may not observe the child in all the various environments in which the child interacts and he/she may behave differently in different environments (Martin, 1988). The third difficulty in rating a child's temperament is that a child may behave differently from one time to the next in the same setting (Martin, 1988).

To attempt to control for these areas of difficulty, Martin, (1988) designed his assessment battery to include observations by three different raters: the parent, the teacher, and the clinician. An analysis of Martin's normative sample revealed low correlations among all three of the rating forms. Factors contributing to the low correlations are: a) different questions used to assess equivalent factors across rater type (parent, teacher, and clinician), b) situational variance is included due to different behaviors seen by the raters in the environment in which they see the child, and c) raters attend to different characteristics because these characteristics vary in salience for each setting. Despite the low correlations among the three rating instruments, the inclusion of ratings from a cross-section of a child's environment by three different individuals will provide a more global assessment of a child's temperamental style.

Analysis of each separate rating scale (parent, teacher, and clinician) revealed strong reliability in internal 
consistency with coefficient alphas ranging from .70 to .90 . Test-retest reliability for the teacher forms ranged from .70 to .85 for the same teacher and from .40 to .65 for different teachers. This same reliability on the parent forms revealed a range of .43 to .70 for mothers and .37 to .62 for fathers. The validity of all forms of this instrument has been reported through relationship to achievement in first grade based on teacher's grades. A correlation of .76 is reported for reading scores as well as a correlation of .65 for math grades.

SUMMARY

The evolution of our understanding of temperament is ongoing. The New York Longitudinal Study (Thomas \& Chess, 1977) was a major study which identified nine distinct categories of temperament. Research since that time has attempted to further define the categories which most accurately reflect temperament. This process has led researchers to identify different numbers and descriptions of categories. Despite this apparent disagreement, there has been general agreement on the constructs of temperament. Temperament is believed to be of constitutional origin and impacts the how of behavior. It is also considered in relationship to environmental demands. If a child's temperamental style is in consonance with his/her environment, the child is perceived as easy. If the child's temperamental style is in disharmony, or dissonance with 
his/her environment, the child is perceived as difficult. Perceptions of temperament are based on goodness of $f i t$. Why is it important to examine a child's temperamental style relative to language development? The entire notion of temperament is how an individual interacts with his/her environment (Thomas \& Chess, 1977; Fullard et. al., 1984). It stands to reason, then, that temperament may be a factor in a child's course of language development.

Many studies have demonstrated a relationship between behavioral disorder and language disorders (Orton, 1937 ; Baker, Cantwell, \& Mattison, 1980; Hargrove, 1984; Baker \& Cantwell, 1982; Chess \& Rosenberg, 1974; Gualtieri et al, 1983; Beitchman et al, 1986; Richman, Stevenson, \& Graham, 1975). We have also seen how temperament is correlated to behavior (Mehregany, 1991; Maziade et al., 1990). We now need to take a more focused look at the contribution of temperament to language development.

The purpose of this study was to compare parent and clinician temperament ratings among three groups of first grade children with varying levels of language development. Review of the literature reveals some distinct relationships between language disorders and behavior disorders. Since our perception of temperament is observed through behavior, it is possible that temperament may be a factor in the development of language. We have examined one study that correlates the temperamental characteristic of affect-extraversion with language scores. We will now look further at additional temperamental characteristics that may give us more 
information about the complex interrelation of factors impacting language development. 
CHAPTER III

METHODS AND PROCEDURES

SUBJECTS

A total of 51 subjects for this study were selected from participants in the Portland Language Development Project (PLDP), a longitudinal study of language development.

\section{Recruitment}

Subjects were originally recruited when they were 20 to 34 months of age through local pediatric offices and newspaper advertisements. After signing a permission form (Appendix B) for their children to be participants in the study, parents of perspective subjects were asked to fill-out a questionnaire (Appendix C) which provided the following information: parental occupation, child's birth date, the number of different words the child used, and whether or not the child put words together to form short sentences.

\section{Diagnostic Group Assignment-Age 2}

Participants were then placed into one of two diagnostic groups: 30 subjects were identified as late talkers (LT) and 30 subjects were identified as having normal language (NL) development. This determination was based on scores on the Language Development Survey (Rescorla, 1989) (Appendix D), a 
checklist of 300 of the most common words in children's early vocabularies. This instrument has been reported to show excellent reliability, validity, and specificity in identifying children with expressive language delay. Those children who used less than 50 words on the LDS and no two word combinations, according to parent report, were considered to be in the LT group. Children who used 50 words or more on the LDS and two word combinations, according to parent report, were considered to be in the NL group.

Subjects were matched as closely as possible for chronological age, race, sex, and socioeconomic status (SES). The SES was based on a 4 factor index combining occupational and education status of the parent(s), resulting in a weighted scores of 1 to 5 , with 1 being the highest SES level and 5 the lowest (Hollingshead, 1975). All subjects passed a hearing screening at $25 \mathrm{~dB} \mathrm{HL}$, received a score of 85 or better on the Bayley Scales of Infant Mental Development (Bayley, 1969), and passed an informal observational screening for neurologic disorders and autism.

A follow-up language evaluation was done on each child at ages 3,4 , kindergarten, and first grade. Table II displays demographic information of the two groups at intake, including mean ages at intake, SES, \# words spoken at intake and sex ratio. 
TABLE II

GROUP DESCRIPTION AT INTAKE

(ine

\begin{tabular}{lllllllll} 
Group & $\mathrm{n}$ & Mean & SD & Mean & SD & Mean & SD & 8Males \\
Normal & 23 & 26.1 & 4.3 & 212.2 & 66.1 & 3.5 & 1.2 & 65 \\
LT & 28 & 24.8 & 3.9 & 29.7 & 26.2 & 3.6 & .8 & 71 \\
\hline
\end{tabular}

*derived from Hollingshead's (1975) four factor scale of social position, on a scale from 1 to 5 , where 1 is the lowest and 5 is the highest SES rating

\section{Follow-up Assessment: First Grade}

Fifty-one of the participants of the original 60 in the longitudinal study were evaluated during their first grade year (ages 75-91 months). Twenty-eight of the children were from the late talkers group (LT) and 23 of the children were from the normal language (NL) group. As part of the language evaluation during the first grade visit, a spontaneous language sample, consisting of 50 utterances, was collected from each child during free play in a clinic room with his/her parent. Each language sample was orthographically transcribed and scored according to Developmental Sentence Scoring (DSS) (Lee, 1974) criteria (Appendix E) which examines grammatical development.

\section{Diagnostic Groups-First Grade}

Late talkers were divided into two subgroups as indexed 
by DSS scores at first grade. The first group consisted of 22 children who were identified as late talkers at intake but had achieved normal language scores by the first grade as indexed by a DSS (Lee, 1974) of 6.35 or greater. This group is referred to as the history of expressive language delay (HELD) group.

The second group consisted of 6 children who were identified as late talkers at intake and continued to show delays in expressive language development in first grade as indexed by a DSS of less than 6.35. This group is referred to as the expressive language delayed (ELD) group.

There were 23 children who were identified as having normal language development at intake. These children demonstrated DSS scores of 6.35 or greater at first grade. This group is referred to as the normal language (NL) group. The demographic make-up of the three groups at first grade follow-up is illustrated in Table III.

TABLE III

GROUP DESCRIPTION AT FIRST GRADE

$\frac{\text { Age }}{\text { (in months) } \quad \text { DSS } \quad \text { SES* }}$

\begin{tabular}{lcccccccc} 
Group & $\mathrm{n}$ & Mean & SD & Mean & SD & Mean & SD & 8Males \\
Normal & 23 & 82.4 & 3.8 & 8.1 & 1.3 & 3.5 & 1.2 & 65 \\
HELD & 22 & 83.2 & 2.6 & 7.7 & 1.0 & 3.6 & .7 & 73 \\
ELD & 6 & 84.2 & 2.8 & 5.5 & .7 & 3.7 & 1.0 & 67 \\
\hline
\end{tabular}

*derived from Hollingshead's (1975) four factor scale of social position 
INSTRUMENTATION

The Lanquage Development Survey (Rescorla, 1989) is a checklist of 300 of the most common words found in young children's vocabularies. This survey has found that parent report of an expressive vocabulary of less than 50 words or no use of two-word combinations by the age of 20-34 months is highly correlated to standardized language measures in toddlers. According to Dale, Bates, Reznick and Morisset (cited in Paul, 1993), the average expressive vocabulary size at 20 months is 155 words with a standard deviation of 87 . Therefore, children who are using an expressive vocabulary of less than 50 words at 20 months fall more than one standard deviation below the mean. This instrument has been reported to be highly reliable, valid, sensitive, and specific in identifying language delay in toddlers.

A Sony Dictator/Transcriber BM-88, a Sony ECM-D8 electret condenser microphone, and Sony brand cassette tapes were used for recording spontaneous language samples.

The Developmental Sentence Scoring (DSS) (Lee, 1974) is an assessment procedure to analyze the syntactic structure and complexity of language in children ages 2 years, 0 months to 6 years, 11 months. A spontaneous language sample is collected containing 50 utterances which have a subject predicate relationship. These sentences are specifically analyzed for components of eight grammatical categories as described by Lee (1974) (see Appendix E). A score of 1 to 8 (1-lowest level of complexity, 8-highest level of complexity) 
is given for each utterance. A total DSS score is derived by adding all 50 sentence scores and dividing by 50 to arrive at a mean. This mean is identified as a child's DSS. The mean is then compared to normative data which has been compiled by Lee (Appendix F). This instrument reports high internal consistency with an overall reliability coefficient of .71 . It also reports high split-half reliability with a coefficient of .73 which indicates good stability of scoring procedures.

The Temperament Assessment Battery for Children (TABC) (Martin, 1988) was selected to rate temperament characteristics of the subjects in the first grade. It is a three-instrument battery of rating scales consisting of Parent, Teacher, and Clinician Forms. These forms are designed to measure temperament characteristics of children ages 3 through 7 years. Only the Parent and Clinician Forms were utilized for this study. The Parent Form (Appendix G) consists of 48 items describing behaviors of children as they occur in the home. The raters score each item on a 7 point rating scale according to the frequency with which the behavior occurs (1-hardly ever, 2-infrequently, 3-once in a while, 4-sometimes, 5-often, 6-very often, or 7-almost always).

Six temperamental variables are rated on the Parent Form of the TABC. These include:
activity
motoric vigor
adaptability
ease and speed of adjustment to new social circumstances 
approach/withdrawal tendency to approach or withdraw from new social situations emotional intensity the vigor of expression of affect, particularly negative affect

ease-of-

management-

through-

distraction

ease with which a child could be (EMTD) distracted away from inappropriate behavior toward appropriate behavior by an adult caretaker.

persistence attention span and tendency to stick with difficult learning or performance situations

(Martin, 1988).

The Clinician Form (Appendix I) is designed to be used in a psychoeducational setting. This form follows the same 7 point rating scale and examines 5 of the 6 temperament variables examined on the Parent Form. The variable of emotional intensity is not included on the Clinician Form due to Martin's (1988) experiential observation that a clinic is a poor place to observe the emotional intensity characteristics of most children. In addition, the variable, ease-of-management-through-distraction (EMTD), is called distractibility on the Clinician Form. Martin notes that this variable has different forms in different environments and it is important to examine the various expressions. The TABC was selected for its multiple rater format. 
According to Martin (1988), subjective rating scales have limitations in four defined areas. Source variance occurs as a result of the rating also being a measure of the frame of reference of the rater as well as a measure of the child's behavior. Situational variance occurs when a child's behavior may be specific to only one situation. Temporal variance occurs when a child behaves in a given way in a given situation at one time but not another. The final type of variance described is instrument variance which occurs when the ratings of a single rater on two different measurement devices thought to measure the same construct are not identical. Martin proposes that the best way to minimize these problems is to collect ratings from more than one rater in more than one setting which will yield a more representative profile of a child's temperament.

Martin (1988) reports the standardization of the Parent Form included a sample group of 1,381 children from three regions of the country, the Teacher Form included a sample of 577 children, and the Clinician Form included a sample of 153 children. All forms reported high internal consistency coefficient alphas to be within a range of .70 to .90 . Interrater reliability was adequate with a reported coefficient alpha of .50 for "normal" subjects. The validity of this instrument is demonstrated through its correlation to achievement. Teacher grades at the end of first grade were correlated to the entire temperament set yielding a correlation of .76 for reading grades and .65 for mathematics grades. 
PROCEDURES

The DSS score for each subject was based on a spontaneous language sample which was collected during a free play session between the subject and his/her parent in a clinic room using a set of Colorforms depicting domestic scenes. Conversational exchanges were recorded for 15 minutes on audiotape and transcribed orthographically by trained graduate student research assistants. Fifty utterances were selected from these transcripts which contained a subject predicate relationship. These utterances were then analyzed utilizing DSS criteria (Appendix E) and a numerical score was given to each utterance. These scores were then totaled for each subject and and a mean calculated. The resulting score determined group assignment for this study.

For purposes of this study, only the Parent Form and Clinician Form of the TABC were utilized. The Parent Forms were completed as part of the first grade follow-up evaluation. Parents were placed in a quiet, distraction free environment to complete the questionnaire. They were instructed to consider their child's behavior within the past three months only. If a question was found to be confusing, parents were instructed to skip that item.

The Clinician Forms were completed by graduate students in speech-language pathology immediately following the first grade evaluation of the subjects' language development. Results from the Parent Form questionnaires were transferred 
to corresponding scoring sheets (Appendix $\mathrm{H}$ ). Results from the Clinician Form questionnaires were tabulated and scored on the same form according to the TABC instructions. $T$-scores were derived from each item on the questionnaires being assigned a raw score of 1-7. All questions relating to a specific temperament variable were then totaled on the scoring sheet. This raw score was then compared to Martin's (1988) normative data to get a T-score. A mean for all Tscores for a specific variable was calculated for each diagnostic group.

\section{DATA ANALYSIS}

The resulting $\mathrm{T}$-scores for each temperament variable were the basis for analysis. The numerical raw score for each question was recorded for the designated temperament variable on the scoring sheet. All raw scores for each item were then added to yield one raw score per factor. This raw score was then compared to the normative data provided by Martin (1988) to obtain a corresponding T-score.

For each group (NL, HELD, ELD), a mean T-score was calculated for each temperament variable. These means were then compared to look for significant differences among the three groups for each of the temperament variables.

Two separate one-way analyses of variance (ANOVA) were conducted. The first ANOVA compared data recorded on the Parent forms. Each of the six individual temperament variables were compared among the three groups. The second 
ANOVA compared data recorded on the clinician forms. The five individual temperament variables were compared in the same manner as the data from the Parent forms. Following the analyses of variance, a Tukey post hoc test was run to determine where significant differences occurred.

since the three sample groups were of unequal number, the Kruskal-Wallis non parametric ANOVA was also run to look for significant differences in the mean ranks of the three groups. Following this analysis, the Mann-Whitney $U$ test was run to determine where significant differences occurred. 
CHAPTER IV

\section{RESULTS AND DISCUSSION}

\section{RESULTS}

The specific objective of this study was to determine if significantly different traits of temperament are exhibited by first grade children with varying levels of language development. The three groups examined included: 23 children with normal language (NL), 22 children with a history of expressive language delay (HELD), and 6 children with chronic expressive language delay (ELD).

The research question asked was: do first grade children with varying levels of language development exhibit significantly different temperament profiles when analyzed on parent and clinician temperament rating forms? Differences were examined on six variables on the Parent Form including: activity, adaptability, approach/withdrawal, emotional intensity, ease-of-management through distraction, and persistence. Differences were also examined on five variables on the Clinician Form including: activity, adaptability, approach/withdrawal, distractibility, and persistence.

The means and standard deviations for each of the dependent measures were computed. The data from the Parent Forms are displayed in Table IV and the data from the Clinician Forms are displayed in Table $\mathrm{V}$. 
TABLE IV

MEANS AND STANDARD DEVIATIONS FOR EACH TEMPERAMENT VARIABLE PARENT FORMS

\begin{tabular}{|c|c|c|c|}
\hline & Normal & $\underline{\text { HELD }}$ & $\underline{E L D}$ \\
\hline Activity & 50.3 & 49.1 & 52.2 \\
\hline SD & 9.7 & 9.4 & 12.0 \\
\hline Adaptability & 48.0 & 47.0 & 41.7 \\
\hline SD & 8.1 & 10.0 & 13.2 \\
\hline Approach/Withdrawal & 51.4 & 45.8 & 41.7 \\
\hline$S D$ & 10.2 & 10.5 & 13.7 \\
\hline Emotional Intensity & 49.6 & 51.5 & 49.7 \\
\hline SD & 9.0 & 10.6 & 9.9 \\
\hline $\begin{array}{l}\text { Ease-of-Management } \\
\text { Through Distraction }\end{array}$ & 44.0 & 44.3 & 39.3 \\
\hline$S D$ & 11.1 & 10.8 & 12.8 \\
\hline Persistence & 52.3 & 49.8 & 44.7 \\
\hline SD & 7.4 & 7.7 & 8.8 \\
\hline
\end{tabular}


TABLE V

MEANS AND STANDARD DEVIATIONS FOR EACH TEMPERAMENT VARIABLE CLINICIAN FORMS

\begin{tabular}{lccc}
\hline & Normal & $\underline{\text { HELD }}$ & $\underline{\text { ELD }}$ \\
\cline { 2 - 3 } & 49.4 & 49.2 & 48.0 \\
SD & 8.0 & 8.8 & 6.0 \\
Adaptability & 50.3 & 46.6 & 52.5 \\
SD & 6.2 & 9.0 & 3.3 \\
Approach/withdrawal & 50.8 & 46.6 & 47.8 \\
SD & 5.0 & 5.2 & 5.8 \\
Distractibility & & & 49.8 \\
SD & 51.3 & 54.5 & 3.0 \\
Persistence & 8.7 & 10.2 & 55.0 \\
SD & 54.3 & 53.9 & 3.7 \\
\hline
\end{tabular}

The data were analyzed to determine whether significant differences existed among the language diagnostic groups of NL, HELD, and ELD on temperament variables rated by parents and clinicians to answer the research question.

Separate analyses of variance (ANOVA) were run for the variables on the Parent Forms and for the variables on the Clinician Forms to look for significant differences on any of the variables between groups. Results of the ANOVA for the 
Parent Forms indicated a p-value of .08 for the variable of approach/withdrawal between the NL group and the ELD group, indicating a trend toward significance on this difference.

A significant difference was found on the Clinician Forms for the variable of approach/withdrawal. A Tukey test showed the significant difference on this variable to exist between the HELD group and the NL group.

Since the sample sizes for the three diagnostic groups were of unequal number, the reliability of the statistical data may be in question. To further analyze the data, the non parametric Kruskal-Wallis test was computed to test for differences between pairs of means. The results of this analysis were in agreement with the parametric ANOVA indicating a significant difference on the temperament variable of approach/withdrawal on the clinician Forms between the HELD group and the NL group. The results of the analyses are displayed in Tables VI and VII.

The results of this study revealed one significant difference on the Clinician Forms for the variable of approach/withdrawal between the NL and the HELD groups; in addition, there was a trend in the same direction on the Parent Forms between the NL and the ELD groups.

\section{DISCUSSION}

The data collected on the Parent Forms to answer the research question regarding differences in temperament profiles among the three language diagnostic groups suggested 
TABLE VI

ANOVA, TUKEY TEST, AND KRUSKAL-WALLIS TEST RESULTS

based on TABC PARENT FORMS

\begin{tabular}{|c|c|c|c|c|c|}
\hline Variable & $\begin{array}{c}\text { ANOVA } \\
\underline{F}\end{array}$ & N/HELD & $\begin{array}{l}\text { TUKEY } \\
\text { N/ELD }\end{array}$ & HELD / ELD & $\begin{array}{l}\text { KRUSKAL- } \\
\text { WALLIS }\end{array}$ \\
\hline Activity & .7793 & NS & NS & NS & \\
\hline Adaptibility & .3558 & NS & NS & NS & \\
\hline Approach/Withdrawal & .0824 & NS & NS & NS & \\
\hline Emotional Intensity & .7884 & NS & NS & NS & \\
\hline $\begin{array}{l}\text { Ease-of-Management } \\
\text { Through Distraction }\end{array}$ & .6124 & NS & NS & NS & \\
\hline Persistence & .0965 & NS & NS & NS & \\
\hline
\end{tabular}

NS - statistically not significant 
TABLE VII

ANOVA, TUKEY TEST, AND KRUSKAL-WALLIS TEST RESULTS based on TABC CLINICIAN FORMS

\begin{tabular}{|c|c|c|c|c|c|}
\hline Variable & $\begin{array}{c}\text { ANOVA } \\
\underline{\mathbf{F}}\end{array}$ & N/HELD & $\begin{array}{l}\text { TUKEY } \\
\text { N/ELD }\end{array}$ & HELD/ELD & $\begin{array}{l}\text { KRUSKAL- } \\
\text { WALLIS }\end{array}$ \\
\hline Activity & .9333 & NS & NS & NS & \\
\hline Adaptibility & .1229 & NS & NS & NS & \\
\hline Approach/Withdrawal & $.0281 *$ & $\mathrm{p}<.05$ & NS & NS & $.0127 *$ \\
\hline Distractibility & .3758 & NS & NS & NS & \\
\hline Persistence & .8956 & NS & NS & NS & \\
\hline
\end{tabular}

* - statistically significant

NS - statistically not significant 
a trend towards a difference on the variable of approach/withdrawal between the NL and ELD groups on parent ratings and a significant difference on approach/withdrawal between the HELD group and NL group on clinician ratings. This variable was designed to measure the tendency to be socially outgoing, versus shy or reserved (Martin, 1988). Differences may be greater on Clinician Forms because when a child feels comfortable and secure, as in the presence of her/his parents, he/she may be more inclined to approach new activities or situations. However, when a child does not feel comfortable and secure, as in circumstances where a stranger (clinician) is observing or attempting to interact with him/her, he/she may withdraw. It is logical that the clinicians might perceive lower approach/withdrawal tendencies in the subjects than the parents observe.

While only HELD differences reached significance, ELD differences showed a trend in the same direction. This suggests low approach/withdrawal tendencies may be a common feature in late talking children. Slomkowski, et al (1992) reported a related finding in their research regarding temperament and language. Their research describes a longitudinal correlation between the temperament variable of high affect-extraversion, which is comparable to Martin's (1988) variable of approach/withdrawal, and language skills at ages 2,3 , and 7 . Specifically noted was the temperament variable of affect-extraversion reported in toddlerhood which was found to make a unique contribution in middle childhood. The research of slomkowski, et al, states that children who 
are more outgoing or extraverted as toddlers have better receptive and expressive language skills at age 3 and are demonstrating stronger advances in receptive skills than less extraverted peers at age 7 . The converse of this finding is reported in this present research. Children with less extraverted (approach), and more withdrawn temperaments may experience varying levels of delay in acquisition of language skills.

The limited significant differences among the diagnostic groups of NL, HELD, and ELD may be related to the differences in sample sizes. The NL group and the HELD group were close to the same size with 23 and 22 subjects, respectively. The ELD group had less than a third the number of subjects than the other two groups in the study. The low number of 6 subjects in the ELD group may have limited the ability to draw conclusions about these results. If the subject groups were of equal size, we may have observed greater significance for the variable of approach/withdrawal on the Parent Forms or we may have seen additional differences among the other temperament variables.

These data suggest that within the HELD group, language skills have developed to within the normal range by the first grade but the temperamental characteristic of low approach/withdrawal exists. It is interesting to note that these subjects were not demonstrating shy characteristics as toddlers according to results of the Childhood Personality Scale (Paul and James, 1990). This may be a long-term effect of the interaction between a child with language delay and 
the communication environment. If a child is experiencing difficulty communicating, he/she may be less likely to engage in social communication and may miss critical opportunities to engage in rich language interactions. The opposite may also be true. If a child is demonstrating shy characteristics, he/she may withdraw from social interactions thereby limiting the type and amount of communication so necessary to increasing language skills. This may be also be true for children in the ELD group. Although this research did not reach statistical significance for the ELD group for the approach/withdrawal variable, a strong trend towards low approach/withdrawal characteristics was noted. 
CHAPTER V

SUMMARY AND IMPLICATIONS

\section{SUMMARY}

Many young children develop language over a broad range of ages, yet present as having normal language development. When language development lags behind what is considered a normal time line, it is important to consider the various factors that may contribute to the delay in development. Since language is a social behavior, temperament, or the how of behavior, must be considered as one of the variables in its development.

The purpose of the current study was to examine various aspects of temperament among three groups of children with varying language histories. The specific question to be answered was, do significant differences occur on parent and clinician questionnaires of temperament among three groups of first grade children demonstrating varying levels of language development: those with NL, those with HELD, and those with ELD?

Subjects for this study included 23 children with normal language (NL), 22 children with a history of expressive language delay (HELD), and 6 children with chronic expressive 
language delay (ELD). The groups were compared on six variables of temperament on Parent Forms including, activity, adaptability, approach/withdrawal, emotional intensity, emotional-management-through-distraction (EMTD), and persistence. The groups were also compared on five variables of temperament on Clinician Forms including, activity, adaptability, approach/withdrawal, distractibility, and persistence.

The data were analyzed to see if significant differences existed between the language diagnostic groups. On measures where an ANOVA test found a significant $\underline{F}$ value $(p<.05)$, a Tukey Test was done to determine where the significant difference among the groups existed. In addition, since the subject groups were of unequal number, the non-parametric Kruskal-Wallis 1-Way ANOVA was also calculated to compare the rank ordered means. On measures where a significant $\underline{F}$ value $(p<.05)$ occurred, a Mann-Whitney $U$ Test was done to determine where the significant difference among the groups existed.

On the Parent Forms, a trend toward low approach/withdrawal characteristics was observed between the NL and ELD groups. On the Clinician Forms, a significant difference was observed on the variable of approach/withdrawal between the NL group and HELD group. Both the parametric ANOVA and non-parametric Kruskal-Wallis analyses were in agreement on this finding. These results suggest a trend for late talking and expressive language delayed children to exhibit low approach/withdrawal characteristics. This tendency may be related to the 
interaction of a child with a language delay and the communication environment.

These results must be viewed tentatively because the sample groups were of unequal numbers. If all the diagnostic groups had been of equivalent size, the results may have yielded stronger significance.

\section{IMPLICATIONS}

\section{$\underline{\text { Research }}$}

The findings of this current study must be substantiated by further research. The usefulness of the present research is limited due to the small size of the ELD group. A duplicate study utilizing sample groups of equal sizes would lend greater significance to the current results.

The current research examined temperament of the sample subjects at first grade. It may be useful to examine the temperamental characteristics of children when they are first identified as language delayed between the ages of 20 to 34 months and compare those results with temperament profiles when the subjects are in first grade. There is a presumption that temperament is innate and changes only slightly as individuals mature. Were these children demonstrating low approach/withdrawal tendencies as preschoolers or have these tendencies changed as the children have matured?

A follow-up longitudinal study between the ages of 10 to 12 may also contribute information regarding the long-term effects of a "shy" personality. Late talkers who demonstrate 
the temperamental characteristic of low approach/withdrawal may demonstrate pragmatic deficits as they enter the middle school years. This information may prove useful in justifying follow-up evaluations within the school age population.

An additional area of further research may be to investigate the possibility of hypersensitivity to various sensory stimuli which may be interpreted as shyness or low approach/withdrawal tendencies in young children. It is possible that what is generally perceived as shyness, may, in fact, be a hypersensitivity to auditory and/or visual stimuli which causes a child to withdraw. If sensory hypersensitivity is implicated as a factor in delayed language development, therapeutic intervention may be focused on sensory integration prior to, or in conjunction with, language intervention.

\section{Clinical}

One might conclude from these results that many children who are language delayed between the ages of 20 to 34 months, without concomitant delays, should not receive early language intervention services because a large number of them may be shy and will outgrow their deficits by the time they are in first grade. Caution should be exercised in making this conclusion. Children who are language delayed and present with a shy personality may be at greater risk for more subtle, pragmatic deficits. These children are less inclined to interact socially and verbally with people 
outside their immediate families thereby missing the opportunity to practice important communication skills and gain a wider range of language input.

Clinically, an awareness of a child's temperamental style may be critical to appropriate program planning. If a child presents with shy characteristics, small group therapy may be warranted within a calm atmosphere. Additionally, techniques for intervention might utilize gentle enticements to participate rather than strong performance requirements. A child with low approach/withdrawal tendencies may feel more safe and secure if he/she has control of when and how to participate. Establishing a trusting rapport with such a child may be essential to successful intervention and might be the first objective. Once rapport is established, language intervention techniques may be more likely to be successful. 
REFERENCES

Baker, L., Cantwell, D., Mattison, R. (1980). Behavior problems in children with pure speech disorders and in children with combined speech and language disorders. Journal of Abnormal Child Psychology, $\underline{8}$, 245-256.

Baker, L., \& Cantwell, D.P. (1982). Psychiatric disorder in children with different types of communication disorders. Journal of Communication Disorders, 15, 113126 .

Baker, L., \& Cantwell, D.P. (1987). Comparison of well, emotionally disordered, and behaviorally disordered children with linguistic problems. Journal of the American Academy of Child Psychiatry, 26, 193-196.

Bates, J. (1989). Concepts and measures of temperament. In G.A. Kohnstamm, J.E. Bates, \& M.K. Rothbart (Eds.), Temperament in Childhood. (3-26). New York: Wiley.

Bates, J. (1983). Issues in the assessment of difficult temperament: A reply to Thomas, Chess, and Korn. Merrill-Palmer Quarterly, 29(1), 89-97.

Bayley, N. (1969). Scales of infant mental development. New York, NY: Psychological Corp.

Beitchman, J.H., Nair, R., Clegg, M., Ferguson, B., \& Patel, P.G. (1986). Prevalence of psychiatric disorders in children with speech and language disorders. Journal American Academy of Child Psychiatry, 24, 528-535.

Bradley, R.H. (1993). Children's home environments, health, behavior, and intervention efforts: A review using the HOME inventory as a marker measure. Genetic, Social, and General Psychology Monographs, 119(4), 437-490.

Buss, A.H. (1991). The EAS theory of temperament. In J. Strelau \& A. Angleitner (Eds.), Explorations in Temperament: International Perspectives on Theory and Measurement (pp. 43-60). New York: Plenum Press.

Buss, A.H., \& Plomin, R. (1975). A temperament theory of personality development. New York: Wiley. 
Buss, A.H., \& Plomin, R. (1984). Temperament: Early Developing Personality Traits. New Jersey: Lawrence Erlbaum Associates.

Carey, W.B. (1970). A simplified method of measuring infant temperament, Journal of Pediatrics, 77, 188-194.

Chess, S., \& Rosenberg, M. (1974). Clinical differentiation among children with initial language complaints. Journal of Autism and Childhood Schizophrenia, 99-109. York: Harper.

Diamond, S. (1957). Personality and temperament. New

Diamond, K.E. (1993). The role of parents' observations and concerns in screening for developmental delays in young children. Topics in Early Childhood Special Education, 13 (1), 68-81.

Emde, R.N., Plomin, R., Robinson, J., Corley, R., DeFries, J., Fulker, D.W., Reznick, J.S., Campos, J., Kagan, R., \& Zahn-Waxler, C. (1992). Temperament, emotion, and cognition at fourteen months: The MacArthur longitudinal twin study. Child Development, 63, 1437-1455.

Eysenck, H. (1953). The Structure of Human Personality. London: Methuen.

Fullard, W.; McDevitt, S.C.; Carey, W.B. (1984). Assessing temperament in one- to three-year-old children. Journal of Pediatric Psychology, 9 (2), 205-217.

Giddan, J.J. (1991). School children with emotional problems and communication deficits: Implications for speech-language pathologists. Lanquage, Speech, and Hearing Services in Schools, 22, 291-295.

Goldberg, S., \& Marcovitch, S.(1989). Temperament in Developmentally Disabled Children. In G.A. Kohnstamm, J.E. Bates, M.K. Rothbart (Eds.), Temperament in Childhood (pp.387-403). Chichester, England: John Wiley \& Sons Ltd.

Gualtieri, C.T., Koriath, U., Van Bourgondien, M., \& Saleeby, N. (1983). Language disorders in children referred for psychiatric services. Journal of the American Academy of Child Psychiatry, 22, 165-171.

Hargrove, P.M. (1984). Common misconceptions about language-impaired children. Pointer, 28, 22-24. 
Heffernan, L.; Black, F.W.; \& Poche, P. (1982). Temperament patterns in young neurologically impaired children. Journal of Pediatric Psychology, $\underline{7},(4), 415-423$.

Hollingshead, A.B. (1975). Four factor index of social status. Unpublished Working Paper. Department of Sociology, Yale University.

Lee, L. (1974) - Developmental Sentence Analysis. Evanston, IL: Northwestern University Press.

Marcovitch, S., Goldberg, S., Lojasek, M. \& MacGregor, D. (1987). The concept of difficult temperament in the developmentally disabled preschool child. Journal of Applied Developmental Psychology, 8, 151-164.

Martin, R.P. (1988). The temperament assessment battery for children. Brandon, Vermont: Clinical Psychology.

Maziade, M.M., Caron, C., Cote, R., Merette, C., Bernier, H., Laplante, B., Boutin, P., Thivierge, J. (1990). Psychiatric status of adolescents who had extreme temperaments at age 7. Psychiatry, 147 (11), 1531-1536.

McDevitt, S.C., \& Carey, W.B. (1978) The measurement of temperament in 3-7 year old children. Journal of Child Psychology and Psychiatry, 19, 245-253.

Mehregany, D.V. (1991). The relation of temperament and behavior disorders in a preschool clinical sample. Child Psychiatry and Human Development, 22 (2), 129-136.

Orton, S.T. (1937). Reading, writing and speech problems in children. New York: Norton.

Paul, R. (1991). Profiles of toddlers with slow expressive language development. Topics in Lanquage Disorders, 11, 1-13.

Paul, R. (1993). Patterns of development in late talkers: preschool years. Journal of Childhood Communication Disorders, 15 (1), 7-14.

Paul, R., \& James, D. (1990). Language delay and parental perceptions. Journal of the American Academy of Child and Adolescent Psychiatry, 29, 669-670.

Paul, R., \& Bauresmith, R. (1991). Narrative skills in four year olds with normal, impaired, and late-developing lanquage. Paper presented at the biennial meeting of the Society for Research in Child Development, Seattle, WA. 
Rescorla, L. (1989). The language development survey: A screening tool for delayed language in toddlers. Journal of Speech and Hearing Disorders, 54, 587-599.

Richman, N., Stevenson, J., \& Graham, P.J. (1975). Prevalence of behavior problems in 3-year-old children: An epidemiological study in a London Borough. Journal of Child Psychology and Psychiatry, 16, 277-287.

Rothbart, M.K., \& Derryberry, D. (1981). Development of individual differences in temperament. In M.E. Lamb, \& A.L. Brown (Eds.), Advances in developmental psychology. $1,37-86$.

Sameroff, A.J. (1974, July). Infant risk factors in developmental deviancy, Paper presented at the International Association for Child Psychiatry and Allied Professions, Philadelphia, PA.

Slomkowski, C.L., Nelson, K., Dunn, J., \& Plomin, R. (1992). Temperament and language: relations from toddlerhood to middle childhood. Developmental Psychology, 28(6), 1090-1095.

Sparks, S.N. (1989). Assessment and intervention with at-risk infants and toddlers: Guidelines for the speechlanguage pathologist. Topics in Lanquage Disorders, $10(1), 43-56$.

Stevenson, J., \& Richman, N. (1978). Behavior, language, and development in three-year-old children. Journal of Autism and Childhood Schizophrenia, 8, 299-313

Tallal, P., Dukett, D., \& Curtiss, S. (1989). Behavioral/emotional profiles of preschool languageimpaired children. Development and Psychopathology. 1 , 51-67.

Thomas, A., \& Chess, S. (1977). Temperament and Development. New York: Brunner/Mazel.

Thomas, A., \& Chess, S. (1982). Reality of difficult temperament. Merrill-Paimer Quarterly, 28(1), 1-19.

Webster's Dictionary of the Enqlish Lanquage (1989). New York: Lexicon Publications, Inc. 
APPENDIX A

HUMAN SUBJECTS APPROVAL 
OFFICE OF GRADUATE STUDIES AND RESEARCH

Research and Sponsored Projects

DATE: October 6, 1995

TO: Loretta M. Kellogg SSN\# 376-62-4427

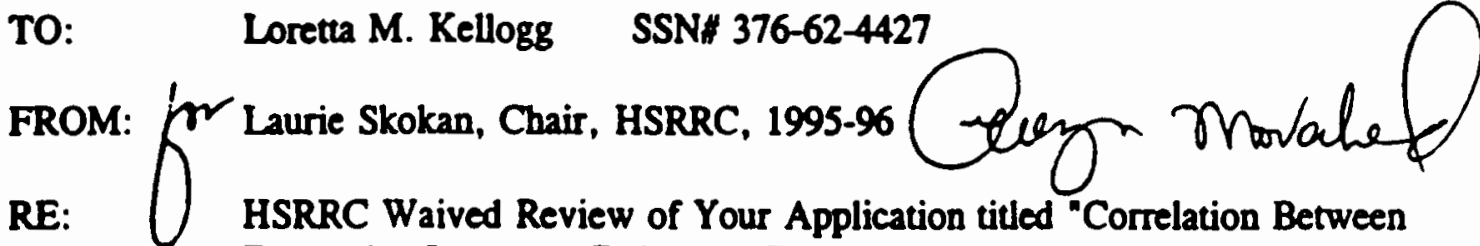
Expressive Language Delay and Temperament"

Your proposal is exempt from further HSRRC review, and you may proceed with the study.

Even with the exemption above, it was necessary by University policy for you to notify this Committee of the Proposed research and we appreciate your timely attention to this matter. If you make changes in your research protocol, the Committec must be notified. This approval is valid for one year from date of issue.

c: $\quad$ Maureen Orr Eldred

Rhea Paul, Project Advisor 
APPENDIX B

PARENT PERMISSION FORM 
INFORMED CONSENT

I, , hereby agree to serve

as a subject in the research project on language development in young children conducted by Rhea Paul.

I understand that the study involves seeing my child yearly for speech and language evaluation and audiotaping conversations between me and my child. I understand that these tapes will be transcribed for analysis of my child's spoken language patterns.

It has been explained to me that the purpose of the study is to learn whether children who begin talking late are at risk for later learning problems.

I may not receive any direct benefit from participation in this study, but my participation may help to increase knowledge which may benefit others in the future.

Dr. Paul has offered to answer any questions I may have about the study and what is expected of me in the study. I have been assured that all information I give will be kept confidential and that the identity of all subjects will remain anonymous.

I understand that I am free to withdraw from participation in this study at any time without jeopardizing my relationship with Portland State University.

I have read and understand the foregoing information.

Date Signature

If you experience problems that are the result of your participation in this study, please contact the secretary of the Human Subjects Research and Review Committee, office of Grants and Contracts, 303 Cramer Hall, Portland State University, 464-3417. 
APPENDIX C

QUESTIONNAIRE FOR PARENTS OF CHILDREN 15-30 MONTHS 
QUESTIONNAIRE FOR PARENTS OF CHILDREN 15-30 MONTHS OLD

What is your child's:

first name?

date of birth?

Mother's (or primary parent's) full name?

Mother's (or primary parent's) phone number?

Mother's occupation?

Father's occupation?

How many different words can your child say? (It's OR if the words aren't entirely clear, as long as you can understand them).

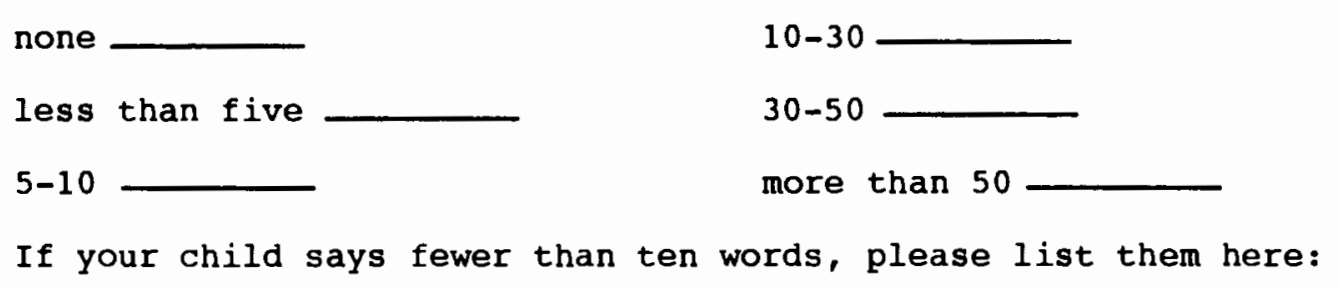

If your child says fewer than ten words, please list them here:

Does your child put words together to form short "sentences"?

Yes No

If yes, please give three examples here:

Would you be interested in participating in later parts of this study?

Yes

No 
APPENDIX D

\section{LANGUAGE DEVELOPMENT SURVEY}

Source: Rescorla, L. (1989). The language development survey: A screening tool for delayed language in toddlers. Journal of Speech and Hearing Disorders, 54, 587-599. 
The Language Development Survey

\begin{tabular}{|c|c|c|c|c|c|c|c|}
\hline FOCD & ANIMALS & ACTIONS & HOUSEHOLD & PERSONAL & CLOTHES & \multicolumn{2}{|c|}{ MODIFIERS OTHERS } \\
\hline$\overline{\text { apple }}$ & bear & bath & bathtub & brush & belt & \multicolumn{2}{|c|}{$\overline{\text { allgone }} \overline{A, B, C, e t c}$} \\
\hline banana & bee & breakfast & bed & comb & boots & all right & away \\
\hline bread & bird & bring & blanket & glasses & coat & \multirow{2}{*}{$\begin{array}{l}\text { had } \\
\text { big }\end{array}$} & booboo \\
\hline butter & bug & catch & bottle & key & diaper & & byebye \\
\hline cake & bunny & clap & bowl & money & dress & \multirow{2}{*}{$\begin{array}{l}\text { black } \\
\text { blue }\end{array}$} & curse words \\
\hline candy & cat & clean & chair & paper & gloves & & here \\
\hline cereal & chicken & close & clok & pen & hat & \multirow{2}{*}{$\begin{array}{l}\text { broken } \\
\text { clean }\end{array}$} & hi, hello \\
\hline cheese & cow & come & crib & pencil & jacket & & in \\
\hline coffee & $\operatorname{dog}$ & cough & cup & penny & mittens & cold & me \\
\hline cookie & duck & cut & door & pocketbook & pajamas & dark & meow \\
\hline crackers & elephant & dance & floor & tissue & pants & \multirow{2}{*}{$\begin{array}{l}\text { dirty } \\
\text { down }\end{array}$} & my \\
\hline drink & fish & dinner & fork & toothbrush & shirt & & myself \\
\hline egg & frog & doodoo & glass & umbrella & shoes & good & nightnight \\
\hline food & horse & down & knife & watch & slippers & \multirow{2}{*}{$\begin{array}{l}\text { happy } \\
\text { heavy }\end{array}$} & no \\
\hline grapes & monkey & eat & light & & sneakers & & off \\
\hline gum & pig & feed & mirror & PEOPLE & socks & \multirow{2}{*}{$\begin{array}{l}\text { heavy } \\
\text { hot } \\
\text { hungry }\end{array}$} & on \\
\hline hamburger & puppy & finish & pillow & aunt & sweater & & out \\
\hline hotdog & snake & $f i x$ & plate & baby & & little & please \\
\hline icecream & tiger & get & potty & & VEHICIES & \multirow{5}{*}{\multicolumn{2}{|c|}{$\begin{array}{ll}\text { mine } & \text { Sesame st. } \\
\text { more } & \text { scuse me } \\
\text { open } & \text { shut up } \\
\text { pretty } & \text { thank you } \\
\text { red } & \text { there }\end{array}$}} \\
\hline juice & turkey & give & radio & daddy & bike & & \\
\hline meat & turtle & go & room & doctor & boat & & \\
\hline milk & & have & sink & girl & bus & & \\
\hline orange & BODY & help & soap & grandma & car & & \\
\hline pizza & BARTS & hit & sofa & grandpa & motorbike & \multirow{3}{*}{\multicolumn{2}{|c|}{$\begin{array}{ll}\text { shut } & \text { under } \\
\text { stinky } & \text { welcame } \\
\text { that } & \text { what }\end{array}$}} \\
\hline pretzel & arm & hug & spoon & lady & plane & & \\
\hline soda & belly & jump & stairs & $\operatorname{man}$ & stroller & & \\
\hline soup & bottom & kick & table & mommy & train & \multirow{3}{*}{\multicolumn{2}{|c|}{$\begin{array}{ll}\text { tnis } & \text { where } \\
\text { tired } & \text { why } \\
\text { up } & \text { woof woof }\end{array}$}} \\
\hline spaghetti & chin & kiss & telephone & own name & trolley & & \\
\hline tea & ear & knock & towel & pet name & truck & & \\
\hline toast & elbow & look & trash & uncle & & \multirow{5}{*}{\multicolumn{2}{|c|}{$\begin{array}{ll}\text { wet } & \text { yes } \\
\text { white } & \text { you } \\
\text { yellow } & \text { yum yum } \\
\text { yucky } & 1,2,3, \text { etc }\end{array}$}} \\
\hline water & eye & love & & Ernie etc & & & \\
\hline & face & lunch & window & & & & \\
\hline TOYS & finger & make & & & & & \\
\hline ball & foot & nap & & & & & \\
\hline balloon & hair & outside & & & & & \\
\hline blocks & hand & pattycake & & & & & \\
\hline book & knee & peekaboo & & & & & \\
\hline bubble & leg & peepee & Please lis & th any other & words your & child uses & here: \\
\hline crayons & mouth & push & & & & & \\
\hline doll & neak & read & & & & & \\
\hline present & nose & ride & & & & & \\
\hline slide & teeth & run & & & & & \\
\hline $\begin{array}{l}\text { swing } \\
\text { teddybear }\end{array}$ & $\begin{array}{l}\text { thumb } \\
\text { toe } \\
\text { turmy }\end{array}$ & $\begin{array}{l}\text { see } \\
\text { show } \\
\text { sing }\end{array}$ & $\begin{array}{l}\text { Does your } \\
\text { (e.g. more }\end{array}$ & $\begin{array}{l}\text { child combin } \\
\text { cookie, car }\end{array}$ & $\begin{array}{l}\text { byo two or mo } \\
\text { byebye, et }\end{array}$ & $\begin{array}{l}\text { re words ir } \\
\text { c. ) yes }\end{array}$ & $\begin{array}{l}\text { n phrases? } \\
\text { no }\end{array}$ \\
\hline OUTDOORS & & sit & Please $1 i$ & $t$ below THRE & E of your & ld's lone & gest and \\
\hline flower & PLACES & sleep & best sent & nces or phra & ses. & & \\
\hline house & church & stop & & & & & \\
\hline mon & home & take & & & & & \\
\hline rain & hospital & throw & & & & & \\
\hline sidewalk & library & tickle & & & & & \\
\hline snow & McDonalds & walk & & & & & \\
\hline star & park & want & This surve & ey instrument & Was deve & ed by & \\
\hline street & school & wash & Leslie Re & corla, Ph.D. & & & \\
\hline sun & store & & & & & & \\
\hline tree & $\mathbf{z} \infty$ & & & & & & \\
\hline
\end{tabular}


APPENDIX E

DEVELOPMENTAL SENTENCE SCORE:

SCORING CRITERIA

Source: Lee, I. (1974). Developmental sentence analysis. Evanston, II: Northwestern University Press. 
The Developmental Sentence Scoring (DSS) Reweighted Scores

\begin{tabular}{|c|c|c|c|c|}
\hline 2000 & 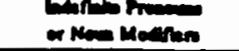 & שוd & Mals Varts & sowny Vart \\
\hline 1 & B. & 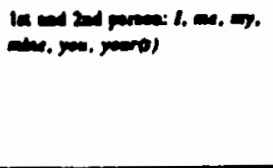 & 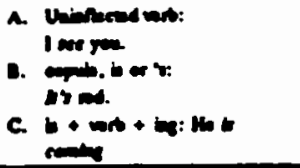 & \\
\hline 2 & & 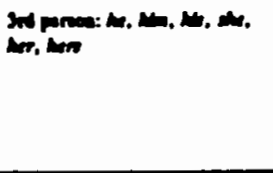 & 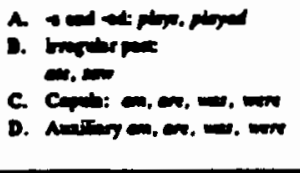 & 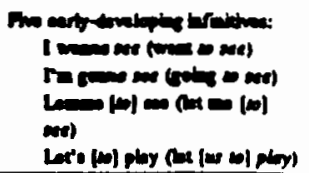 \\
\hline 3 & A. & 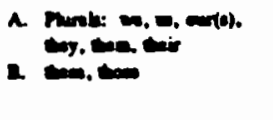 & & 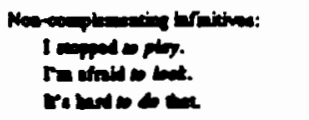 \\
\hline 4 & enter. & & 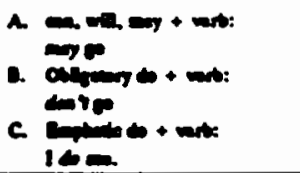 & 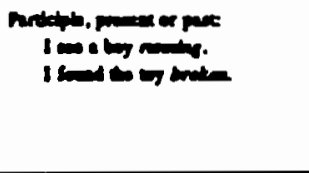 \\
\hline s & ' & 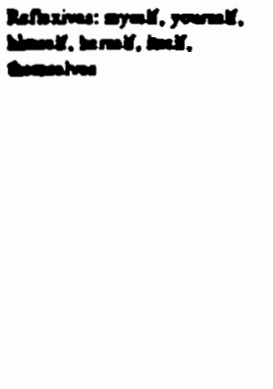 & & 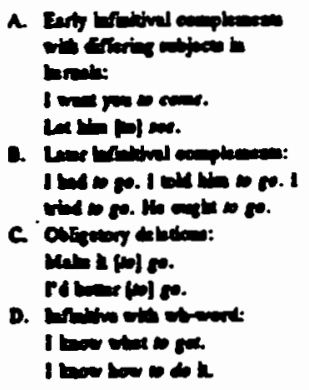 \\
\hline 6 & & 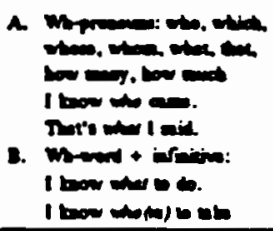 & 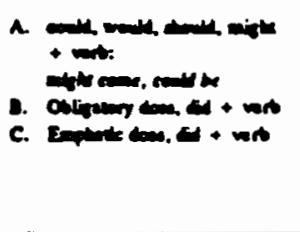 & \\
\hline 7 & 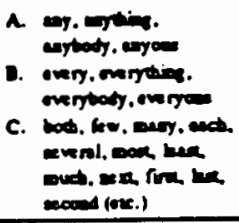 & 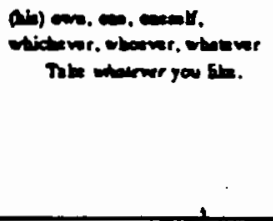 & 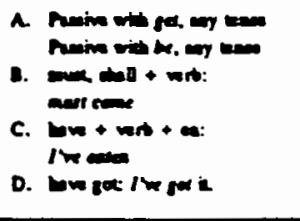 & 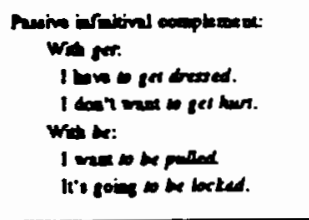 \\
\hline 1 & & & 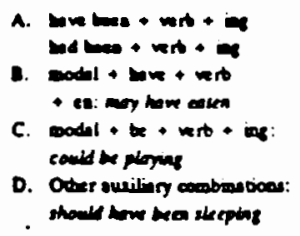 & 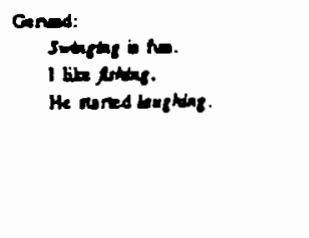 \\
\hline
\end{tabular}




\begin{tabular}{|c|c|c|c|c|}
\hline Score & Negutives & Conjunctions & Interrogutive Revernals & W-Quertions \\
\hline 1 & 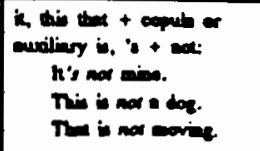 & & 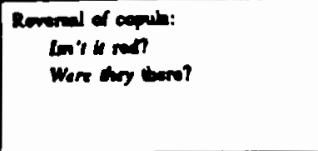 & \\
\hline 2 & & & & 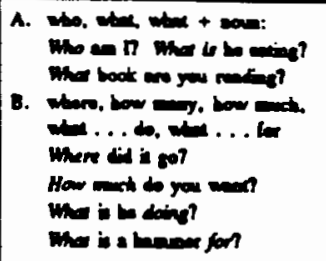 \\
\hline 3 & & $=1$ & & \\
\hline 4 & Ch & & 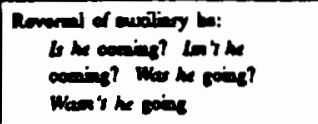 & \\
\hline 3 & $i=2$ t & 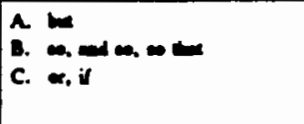 & & 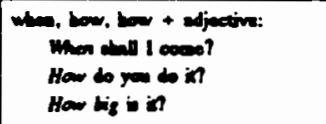 \\
\hline 6 & & beomenes & 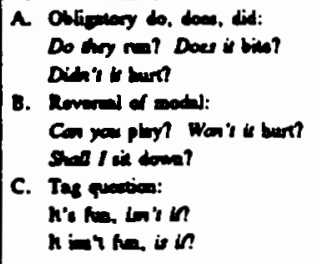 & \\
\hline 7 & 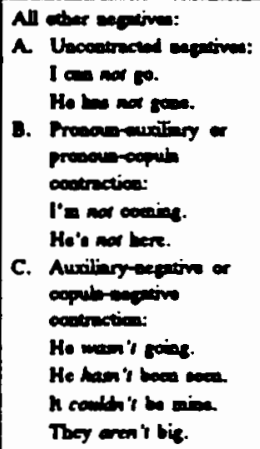 & & & 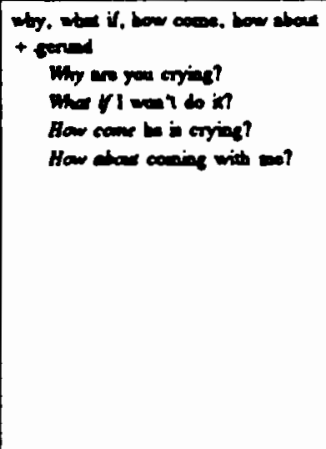 \\
\hline 8 & & 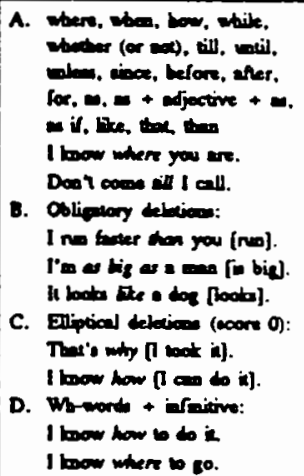 & 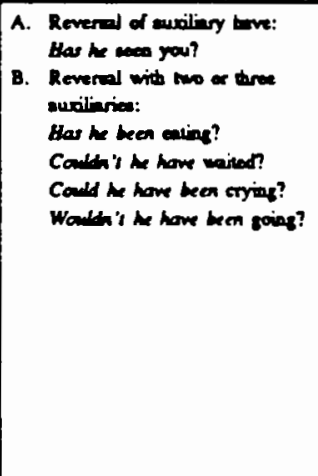 & 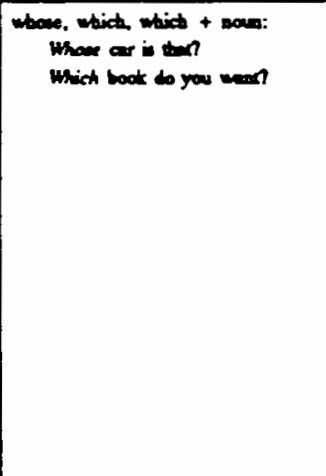 \\
\hline
\end{tabular}




\begin{abstract}
APPENDIX F
DEVELOPMENTAL SENTENCE SCORE:

NORMS
\end{abstract}

Source: Lee, I. (1974). Developmental sentence analysis. Evanston, IL: Northwestern University Press. 


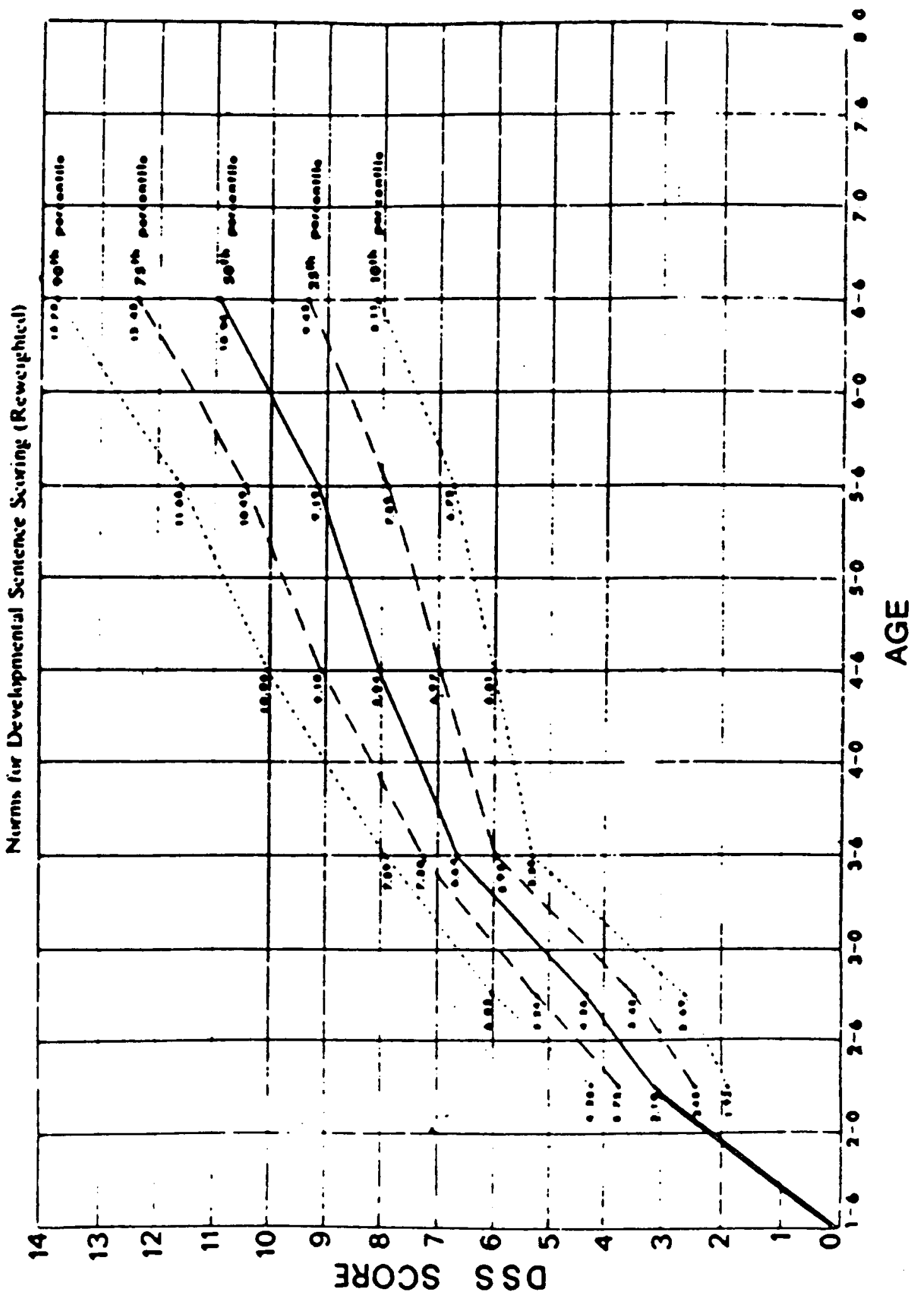


APPENDIX G

TEMPERAMENT ASSESSMENT BATTERY FOR CHILDREN (TABC):

PARENT RATING FORM

Source: Martin, R.P. (1988). The temperament

assessment battery for children. Brandon, Vermont: clinical Psychology. 


\section{TEMPERAMENT ASSESSMENT BATTERY FOR CHILDREN}

\section{Parent Form}

Child's
Name
(Circh)

Aespondenits

Name
Age (in

Monins) Date

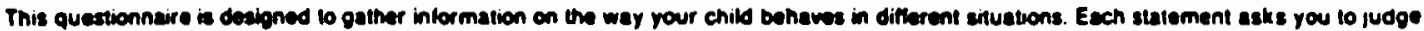

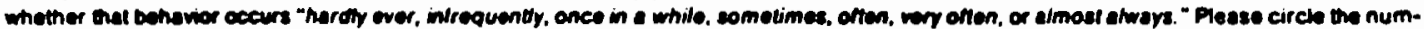

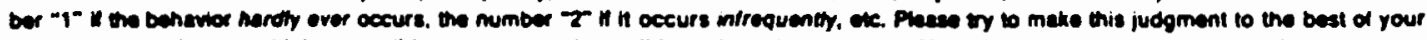
bility, based on how you bink you child compares bo other children about the eume ege. Abo, please make these judgments based on your child's benavior during the last 9 months.

\begin{tabular}{|c|c|c|c|c|c|c|}
\hline $\begin{array}{c}1 \\
\text { nerdy } \\
\text { nex }\end{array}$ & $\frac{2}{\text { Wincquenthy }}$ & ${ }_{\text {enco }}^{3}$ & comatime & $\sin$ & $\begin{array}{c}1 \\
\cos y\end{array}$ & $\begin{array}{c}7 \\
\text { elmost } \\
\text { alway }\end{array}$ \\
\hline
\end{tabular}

1.1 My child be shy whe sulte he/she does not know.

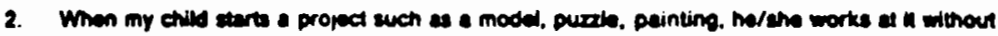
stopping unte complited, owen id h takea a long time.

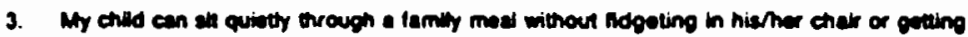
out of ntaver chers.

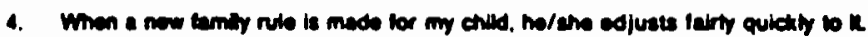

5. My enid cries end sereams co hard ho/she gots red in the lece and short of breach

6. In my child b in a bed mood. ho/ene cen eadly be paked oul of $n$

7. When firt meoting now children. my child b beshrul.

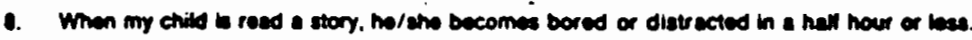

9. My child buncomlortable showing of a performing in front of new viettors to tha home.

10. My child b at ease within a fow vists when visting of someone dasis home.

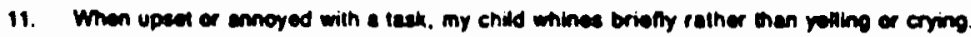

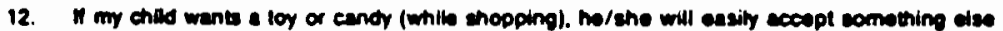
ofiered instand.

13. Wmen my child mowes about in the houce of ouldoors. he/she runs pather then walke.

14. It desired ouldoor setivily must be postponed due to bed weather. my child sture disappointed lor most of the day.

15. My child prelers active games unvolung running and jumping. olc.. rather then games in which ho/she must sit

16. It my child resists some procedure. such as hanng hair cut. brushed. or washed, ma/she will continue 10 resist it for at bast several months.

17. When taken sway trom an actinity my child enjoys. ha/ghe tends 10 prolest strongty. by intense lussing

18. When my child is promised something in the future, he/sne constanlly keops reminding parents.

19 When in the part, at a party. Or visiting. my child will go up to strange children and join in there play.

20 If my child is shy with a strange adull ne/sne gurekly (within a hall nour or sol gets over this.

21. My child sits still to have a story told or read. or a song sung

$\begin{array}{lllllll}1 & 2 & 3 & 4 & 5 & 6 & 7 \\ 1 & 2 & 3 & 4 & 5 & 6 & 7 \\ 1 & 2 & 3 & 4 & 5 & 6 & 7 \\ 1 & 2 & 3 & 4 & 5 & 6 & 7 \\ 1 & 2 & 3 & 4 & 5 & 6 & 7 \\ 1 & 2 & 3 & 4 & 5 & 6 & 7 \\ 1 & 2 & 3 & 4 & 5 & 6 & 7 \\ 1 & 2 & 3 & 4 & 5 & 1 & 7 \\ 1 & 2 & 3 & 4 & 5 & 6 & 7 \\ 1 & 2 & 3 & 4 & 5 & 6 & 7 \\ 1 & 2 & 3 & 4 & 5 & 6 & 7 \\ 1 & 2 & 3 & 4 & 5 & 6 & 7 \\ 1 & 2 & 3 & 4 & 5 & 6 & 7 \\ 1 & 2 & 3 & 4 & 5 & 6 & 7 \\ 1 & 2 & 3 & 4 & 5 & 6 & 7 \\ 1 & 2 & 3 & 4 & 5 & 6 & 7 \\ 1 & 2 & 3 & 4 & 5 & 6 & 7 \\ 1 & 2 & 3 & 4 & 5 & 6 & 7 \\ 1 & 2 & 3 & 4 & 5 & 6 & 7 \\ & 2 & 3 & 4 & 5 & 6 & 7 \\ 1 & 3 & 4 & 5 & 6 & 7\end{array}$




\begin{tabular}{|c|c|c|c|c|c|c|}
\hline $\begin{array}{c}1 \\
\text { nerdy } \\
n \times y\end{array}$ & $\stackrel{2}{2}$ & $\begin{array}{c}3 \\
\text { enco h }\end{array}$ & 4 & $\stackrel{s}{\operatorname{cin}}$ & $\begin{array}{c}6 \\
\text { men } \\
\text { onen }\end{array}$ & $\begin{array}{c}7 \\
\text { almoxt } \\
\text { chays }\end{array}$ \\
\hline
\end{tabular}

22. When ecolded or reprimended by parents. my child reacts mildy. uch es wining or complaining, rater than etronghy. with aring or scereaming.

23. When my child becomes engry about something. It is difficull to sodreck Manher.

24. When learning a new phrical ecturty (ach as nopping. skaling. bike riding). my child wilf sound long periods at umo precteine.

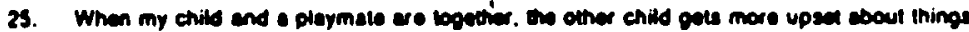
(tharing tort. tahing turns, olc.) then my child.

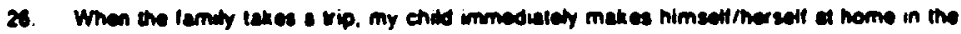
new suroundinge.

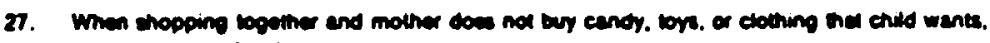
maleno crive end yolle.

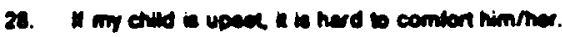

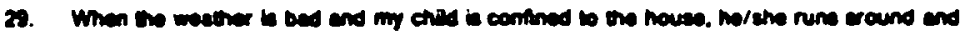

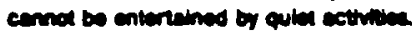

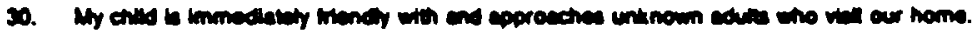

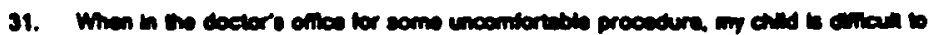

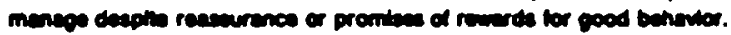

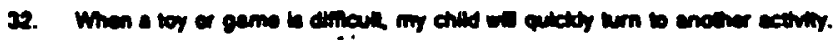

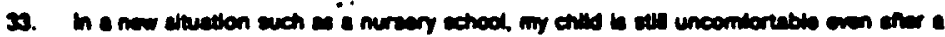
ingerse

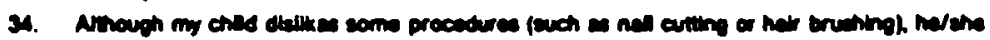

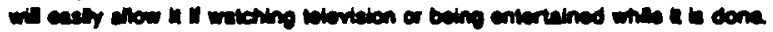

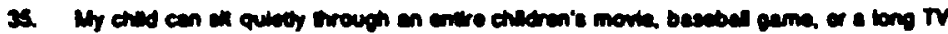
eregrem.

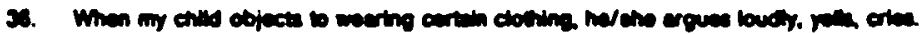

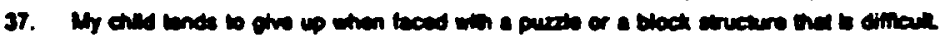

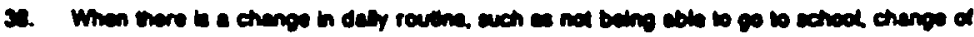

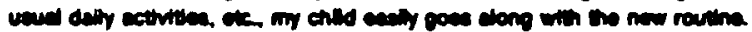

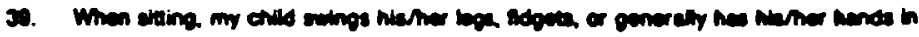
contant motion.

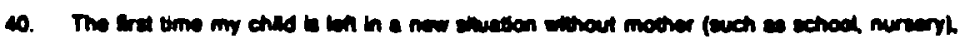
mathe gets upext

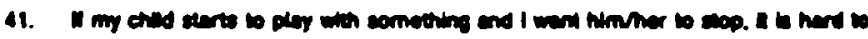

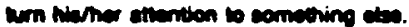

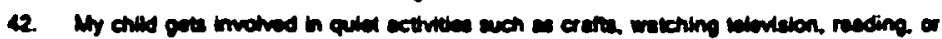
looting at peture books

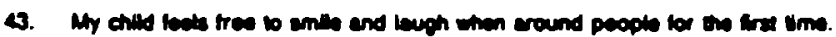

4. When wey from nome fror exampis. on vecetionl. my child hes dificulity in edjusting to routines end schedules that ere differem trom thoes at home.

45. My child seems to uke ininge mane-d-1ectly. cocepls ements in strice without gerting very exeited.

46. When plarng with a triend. my child gots bored with one ectivity sooner than the orer child.

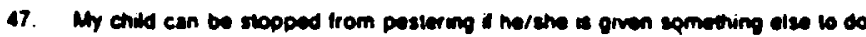

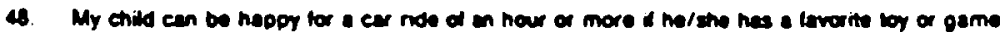
10 oley win.

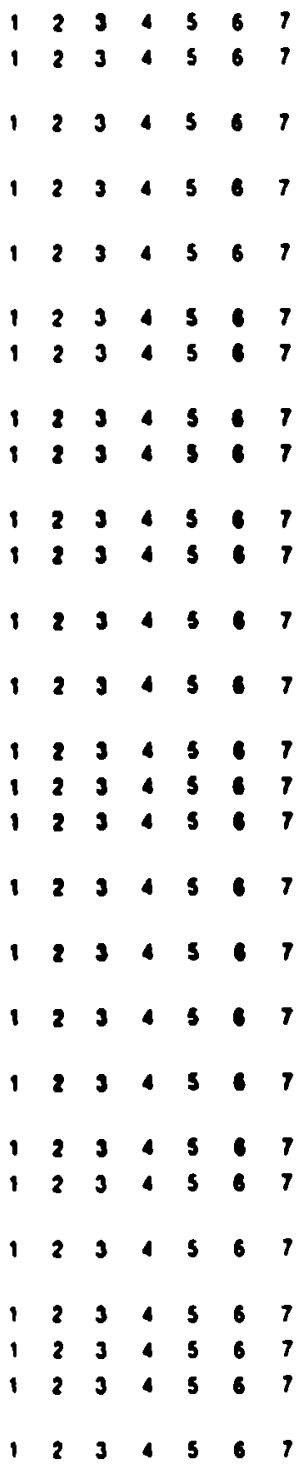

1234567

1234567

$\begin{array}{lllllll}1 & 2 & 3 & 5 & 6 & 7\end{array}$

1254567

$8345 \div 7$

1234517

1254507

234567

$12345 \bullet 7$

1234507

12345.7

1234567

12345,7

1234567

1234567

234567

1234567

34567

4567

$\begin{array}{llllll}2 & 3 & 5 & 6 & 7\end{array}$

1234567

Thonk You 
APPENDIX H

TEMPERAMENT ASSESSMENT BATTERY FOR CHILDREN (TABC):

PARENT SCORING SHEET

Source: Martin, R.P. (1988). The temperament

assessment battery for children. Brandon, Vermont: Clinical Psychology. 
Child's

Age (in

Name

Months)

Date

Sex M F Ethnicity Caucasian, Black, Hispanic, Oriental,

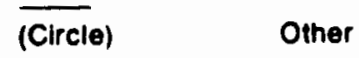

(circle one)

Respondent's

Name
Relation: Father, Mother

Other

\begin{tabular}{|c|c|c|c|c|c|c|c|c|c|c|c|c|}
\hline $\begin{array}{c}\text { Temperament } \\
\text { Scale }\end{array}$ & & & & & em & & & & Sum & $\begin{array}{l}\text { Prorated } \\
\text { Sum }\end{array}$ & $\begin{array}{c}T \\
\text { Score }\end{array}$ & $\begin{array}{l}\text { Verbal } \\
\text { Labels }\end{array}$ \\
\hline \multirow[t]{2}{*}{ Activity } & & $\longrightarrow$ & - & - & - & 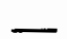 & - & - & $\longrightarrow$ & 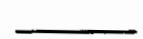 & - & $\longrightarrow$ \\
\hline & $\begin{array}{c}3 \\
\text { (R) }\end{array}$ & 13 & 15 & $\begin{array}{c}21 \\
\text { (R) }\end{array}$ & 29 & $\begin{array}{c}35 \\
\text { (R) }\end{array}$ & 39 & $\begin{array}{l}42 \\
\text { (R) }\end{array}$ & & & & \\
\hline
\end{tabular}

Adaptability

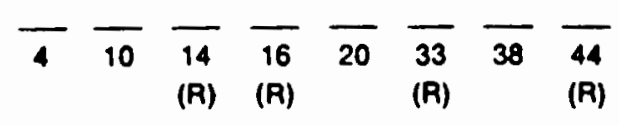
(R) (R)
(R)
(R)

Approach/

Withdrawal

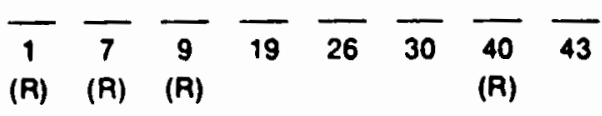

Emotionai

Intensity

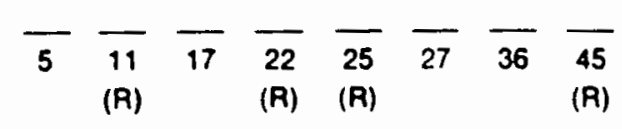
(R)
(R) (A)
(A)

Ease-ot-

Management-

Through-

Distraction

(EMTD)

$$
\begin{aligned}
& \begin{array}{lllllll}
6 & \overline{12} & \overline{23} & \overline{28} & \overline{31} & \overline{34} & \overline{41}
\end{array} \\
& \text { (R) (R) (R) }
\end{aligned}
$$

Persistence

$$
\begin{array}{llllllll}
2 & \begin{array}{lllll}
8 \\
(R)
\end{array} & 18 & \overline{24} & \overline{32} & 37 & 46 & 48 \\
& & \text { (R) } & \text { (R) } & \text { (R) }
\end{array}
$$

(c) 1988 CPPC. All rights reserved. 


\author{
APPENDIX I \\ TEMPERAMENT ASSESSMENT FOR CHILDREN (TABC): \\ CLINICIAN RATING FORM/SCORING SHEET
}

Source: Martin, R.P. (1988). The temperament

assessment battery for children. Brandon, Vermont: Clinical Psychology. 


\section{TEMPERAMENT ASSESSMENT BATTERY FOR CHILDREN}

Clinician Form

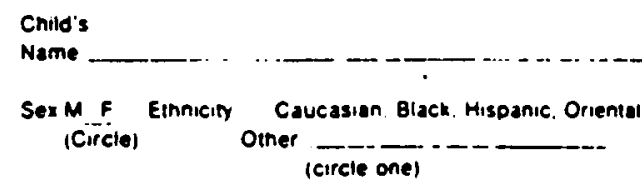

Examiner's

Name _-_ - -............

Age (m

Months)$$
\text { leircle or }
$$

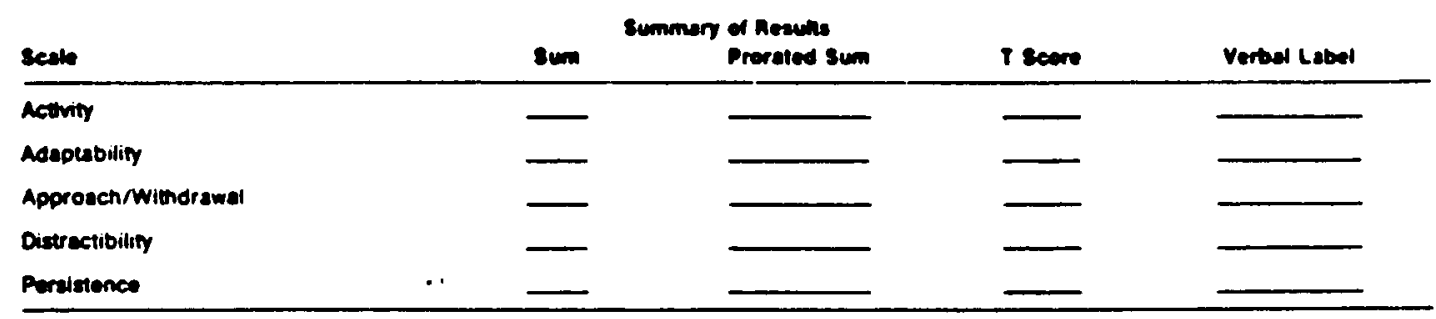

anting

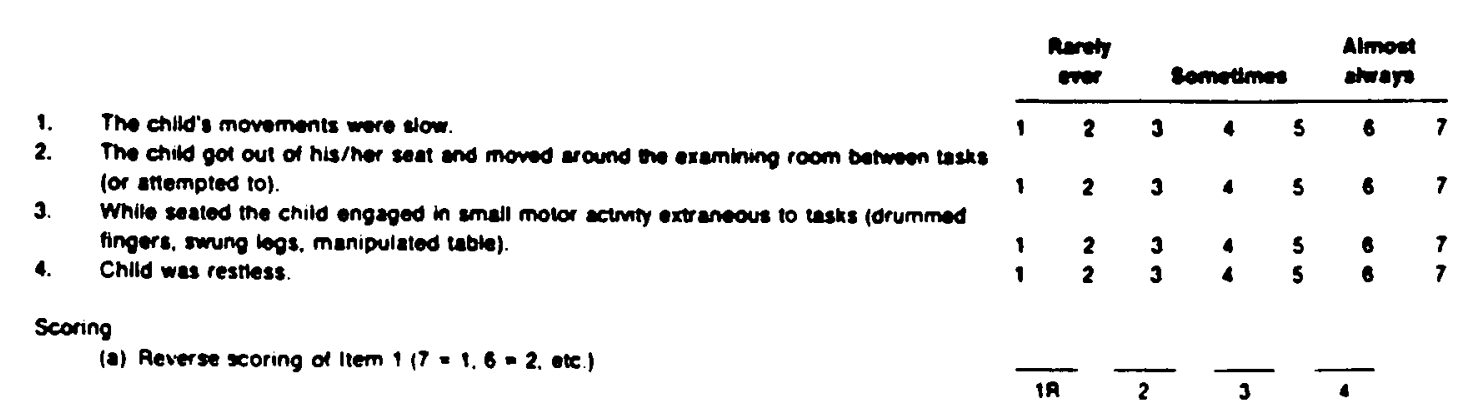

(b) Carculate sum

Total = 
Adapeability

1. The child quickly adjusted to the examiner and the testing smuation

Ghild had difliculty in transition trom one task to the naxt

When clinician attempted to direct child's inappropriate denavior by establishing rules for the session (let's stay in our seat). child was quick to adjust to new rule.

4. The child quickty began to display postural behamor appropriate for an examinee of his/her age (e.9.. sat in seat. Oriented body toward materials. etc )

5. The child appeared anxious and tense during the examination

Scoring

(a) Reverse scoring of ltems 2 and $5(7=1,6=2$, etc.)

(b) Calculate sum

Totel *

\section{Apprescervithdrene}

1. Child was thy in prosence of ctinicten.

2. Child wes initially hesitant to antempt new tasks.

3. Child readily pertormed for clinicien, sometimes "showing oft." Seemed to enjoy demonstrating stills.

4. Child initlated conversations with clinicten.

5. Child soemed relaxed and comtortsble with clinielen.

Scoring

(a) Roverse scoring of hems 1 and $2(7=1,6=2$, otc.)

(b) Calculate sum

$$
\text { Total }=
$$

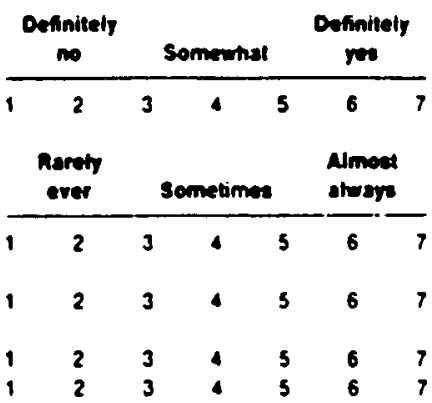

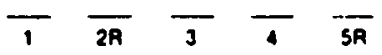

\begin{tabular}{|c|c|c|c|c|c|c|}
\hline \multicolumn{2}{|c|}{ mers } & \multicolumn{3}{|c|}{ Comedines } & \multicolumn{2}{|c|}{$\frac{A m a n}{\cos }$} \\
\hline 1 & 2 & 3 & 4 & 5 & 6 & 7 \\
\hline 1 & 2 & 3 & 4 & 5 & 6 & 7 \\
\hline 1 & 2 & 3 & 4 & 5 & 6 & 7 \\
\hline 1 & 2 & 3 & 4 & 5 & 6 & $r$ \\
\hline 1 & 2 & 3 & 4 & 5 & 6 & 7 \\
\hline
\end{tabular}

19 $\frac{}{2 R} \frac{}{3} \frac{}{5}$ 


\section{Didiractibility}

Childs attention to lasks was easidy udetracked

men engeged in s usk or conversution. nouses outsude room. parents' comments or movement interrupled the child's behamot

3. The child appeared to be daydreaming 109 : asked to have items repeated; didn't seem to the hasening to drections!

4. Aoom temperature. itchy or thont clothng. uncomionable seat. colors distracted child Irom lask.

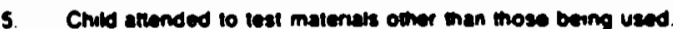

\begin{tabular}{cccccc}
$\begin{array}{c}\text { Harey } \\
\text { mes }\end{array}$ & \multicolumn{2}{c}{ Semetimes } & $\begin{array}{c}\text { Almost } \\
\text { abmars }\end{array}$ \\
\hline 2 & 3 & 4 & 5 & 6 & 7 \\
2 & 3 & 4 & 5 & 6 & 7 \\
2 & 3 & 4 & 5 & 6 & 7 \\
2 & 3 & 4 & 5 & 6 & 7 \\
2 & 3 & 4 & 5 & 6 & 7
\end{tabular}

Scoring

(a) Caraulate sum

Toted -

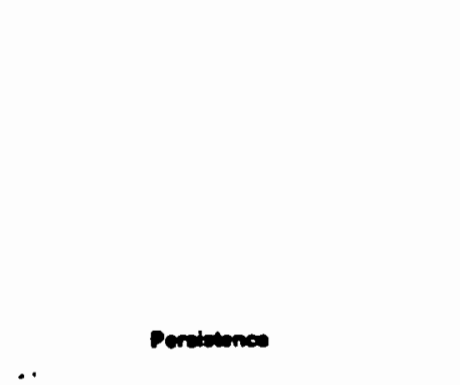

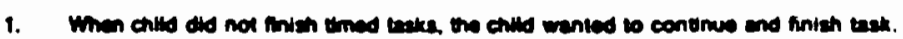

2. The chid quictly responded wh a wong enswer of 7 don't know."

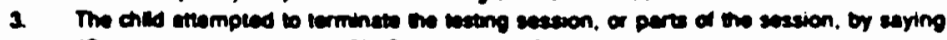

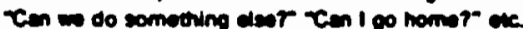

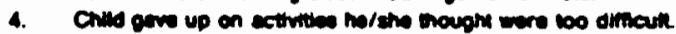

\begin{tabular}{|c|c|c|c|c|c|c|}
\hline \multicolumn{2}{|c|}{ Neres } & \multicolumn{3}{|c|}{ semedtume } & \multicolumn{2}{|c|}{$\begin{array}{l}\text { Almext } \\
\text { chers }\end{array}$} \\
\hline 1 & 2 & 3 & 4 & $s$ & 6 & \\
\hline 1 & 2 & 3 & 4 & $\mathbf{s}$ & 8 & 7 \\
\hline 1 & 2 & 3 & 4 & $\mathbf{s}$ & 6 & 7 \\
\hline 1 & 2 & 3 & 4 & 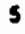 & 6 & 7 \\
\hline & |' & & net & & $\begin{array}{c}\text { onithe } \\
\text { res }\end{array}$ & \\
\hline
\end{tabular}

5. The chid's abilin to remain atrentive unrough the examination eppeared to be ege eppreprivto.

1234567

Sooring

(a) Rowerse scoring of noms 2. 3, and 4 (7 - 1.6 - 2. olc.)

$\bar{I} \quad \overline{2 R} \quad \overline{3 R} \quad \overline{4 R} \quad \overline{5}$

(b) Cacalate sum

Total = 
APPENDIX J

TEMPERAMENT ASSESSMENT BATTERY FOR CHILDREN (TABC)

RAW SCORES 
RAW SCORES FROM TABC

NORMAL LANGUAGE (NL) SUBJECTS

Parent Forms

TEMPERAMENT VARIABLES

\begin{tabular}{ccccccc} 
Subject\# & Act & Adap & Appr/with & Emot & EMTD & Pers \\
\hline 4 & 30 & 48 & 51 & 33 & 41 & 43 \\
9 & 40 & 47 & 54 & 26 & 42 & 38 \\
14 & 29 & 54 & 47 & 16 & 51 & 48 \\
27 & 24 & 47 & 55 & 26 & 39 & 45 \\
40 & 21 & 52 & 40 & 19 & 51 & 40 \\
50 & 36 & 36 & 22 & 22 & 34 & 33 \\
56 & 22 & 43 & 26 & 25 & 29 & 44 \\
58 & 30 & 42 & 34 & 30 & 39 & 39 \\
59 & 22 & 51 & 39 & 17 & 36 & 41 \\
72 & 37 & 36 & 32 & 27 & 35 & 33 \\
81 & 36 & 43 & 42 & 27 & 43 & 43 \\
95 & 28 & 38 & 30 & 23 & 30 & 39 \\
113 & 25 & 47 & 32 & 13 & 49 & 42 \\
126 & 14 & 50 & 36 & 11 & 55 & 48 \\
128 & 20 & 48 & 48 & 20 & 37 & 43 \\
129 & 14 & 43 & 38 & 23 & 44 & 43 \\
130 & 25 & 51 & 42 & 24 & 45 & 37 \\
131 & 23 & 50 & 43 & 19 & 38 & 50 \\
132 & 21 & 46 & 39 & 24 & 44 & 49 \\
139 & 21 & 40 & 23 & 18 & 39 & 39 \\
141 & 23 & 45 & 44 & 23 & 38 & 43 \\
144 & 30 & 41 & 39 & 32 & 31 & 39 \\
150 & 32 & 50 & 47 & 26 & 37 & 36
\end{tabular}


RAW SCORES FROM TABC

HISTORY OF EXPRESSIVE LANGUAGE DELAY (HELD) SUBJECTS Parent Forms

TEMPERAMENT VARIABLES

Subject\# Act

$6 \quad 36$

7

12

19

39

$41 \quad 26$

57

84

86

87

92

97

98

101

102

105

107

109

114

119

122

142
36

29

24

36

23

26

18

21

24

27

23

18

18

40

19

18

32

19

35

24

22
Adap Appr/With

Emot

25

47

42

14

30

47

26

33

51

39

25

39

32

33

43

32

38

34

41

40

22

37
25

25

23

28

25

12

24

14

21

35

24

22

33

16

23

30

14

38

21

24

28

24
45

50
EMTD

Pers

$\begin{array}{ll}46 & 29 \\ 30 & 45 \\ 40 & 46 \\ 33 & 37\end{array}$

41

40

47

44

36

39

50

40

37

30

38

42

40

42

38

37

50

44

45

43

37

41

45

48

37

38

29

45

34

34

36

41

44

53

42 
RAW SCORES FROM TABC

EXPRESSIVE LANGUAGE DELAY (ELD) SUBJECTS

Parent Forms

TEMPERAMENT VARIABLES

Subject\# Act Adap Appr/With Emot EMTD Pers

$\begin{array}{lllllll}15 & 12 & 41 & 39 & 18 & 44 & 34 \\ 29 & 34 & 42 & 38 & 31 & 33 & 31 \\ 93 & 17 & 53 & 44 & 20 & 46 & 45 \\ 94 & 29 & 46 & 24 & 15 & 42 & 35 \\ 100 & 23 & 40 & 27 & 26 & 34 & 42 \\ 111 & 40 & 28 & 14 & 27 & 22 & 34\end{array}$


RAW SCORES FROM TABC

NORMAL LANGUAGE (NL) SUBJECTS

Clinician Forms

TEMPERAMENT VARIABLES

Subject\# Act Adap Appr/With Dist Pers

\begin{tabular}{|c|c|c|c|c|c|}
\hline 4 & 13 & 28 & 27 & 13 & 24 \\
\hline 9 & 24 & 15 & 22 & 28 & 16 \\
\hline 14 & 10 & 30 & 23 & 10 & 28 \\
\hline 27 & 27 & 24 & 34 & 18 & 23 \\
\hline 40 & 13 & 24 & 20 & 13 & 23 \\
\hline 50 & 10 & 29 & 26 & 10 & 28 \\
\hline 56 & 10 & 29 & 23 & 11 & 27 \\
\hline 58 & 10 & 29 & 25 & 11 & 28 \\
\hline 59 & 9 & 30 & 27 & 11 & 28 \\
\hline 72 & 12 & 25 & 17 & 14 & 24 \\
\hline 81 & 22 & 26 & 30 & 17 & 25 \\
\hline 95 & 16 & 28 & 23 & 19 & 19 \\
\hline 113 & 11 & 30 & 26 & 10 & 28 \\
\hline 126 & 9 & 32 & 29 & 6 & 25 \\
\hline 128 & 14 & 29 & 29 & 5 & 34 \\
\hline 129 & 18 & 21 & 26 & 18 & 23 \\
\hline 130 & 12 & 30 & 27 & 12 & 29 \\
\hline 131 & 17 & 29 & 23 & 11 & 30 \\
\hline 132 & 16 & 26 & 27 & 20 & 23 \\
\hline 139 & 15 & 30 & 24 & 10 & 31 \\
\hline 141 & 15 & 30 & 27 & 11 & 28 \\
\hline 144 & 13 & 29 & 27 & 20 & 21 \\
\hline 150 & 20 & 24 & 27 & 20 & 23 \\
\hline
\end{tabular}


RAW SCORES FROM TABC

HISTORY OF EXPRESSIVE LANGUAGE DELAY (HELD) SUBJECTS Clinician Forms

TEMPERAMENT VARIABLES

$\begin{array}{cccccc}\text { Subject\# } & \text { Act } & \text { Adap } & \text { Appr/with } & \text { Dist } & \text { Pers } \\ 6 & 16 & 22 & 25 & 18 & 23 \\ 7 & 18 & 16 & 26 & 17 & 21 \\ 12 & 16 & 28 & 21 & 13 & 26 \\ 19 & 12 & 24 & 12 & 12 & 26 \\ 39 & 24 & 15 & 21 & 25 & 20 \\ 41 & 12 & 31 & 27 & 14 & 30 \\ 57 & 10 & 27 & 21 & 12 & 26 \\ 84 & 9 & 29 & 20 & 10 & 28 \\ 86 & 25 & 26 & 27 & 26 & 25 \\ 87 & 24 & 18 & 22 & 25 & 20 \\ 92 & 10 & 30 & 26 & 10 & 30 \\ 97 & 15 & 17 & 17 & 22 & 16 \\ 98 & 7 & 34 & 21 & 5 & 34 \\ 101 & 17 & 26 & 25 & 25 & 25 \\ 102 & 23 & 15 & 25 & 23 & 16 \\ 105 & 9 & 27 & 24 & 14 & 31 \\ 107 & 11 & 28 & 22 & 11 & 29 \\ 109 & 16 & 24 & 22 & 16 & 21 \\ 114 & 13 & 26 & 25 & 16 & 25 \\ 119 & 9 & 29 & 25 & 13 & 26 \\ 122 & 12 & 30 & 24 & 11 & 27 \\ 142 & 12 & 28 & 16 & 10 & 29\end{array}$




$$
\begin{gathered}
\text { RAW SCORES FROM TABC } \\
\text { EXPRESSIVE LANGUAGE DELAY (ELD) SUBJECTS } \\
\text { Clinician Forms }
\end{gathered}
$$

TEMPERAMENT VARIABLES

\begin{tabular}{cccccc} 
Subject\# & Act & Adap & Appr/with & Dist & Pers \\
\hline 15 & 15 & 30 & 31 & 13 & 21 \\
29 & 16 & 29 & 26 & 15 & 26 \\
93 & 17 & 27 & 21 & 12 & 25 \\
94 & 8 & 30 & 19 & 10 & 29 \\
100 & 10 & 30 & 21 & 12 & 29 \\
111 & 17 & 25 & 22 & 15 & 25
\end{tabular}




\section{APPENDIX K}

TEMPERAMENT ASSESSMENT BATTERY FOR CHILDREN (TABC)

T-SCORES 


$$
\begin{gathered}
\text { T-SCORES FROM TABC } \\
\text { NORMAL LANGUAGE (NL) SUBJECTS } \\
\text { Parent Forms }
\end{gathered}
$$

TEMPERAMENT VARIABLES

subject Act Adap Appr/With Emot

Pers

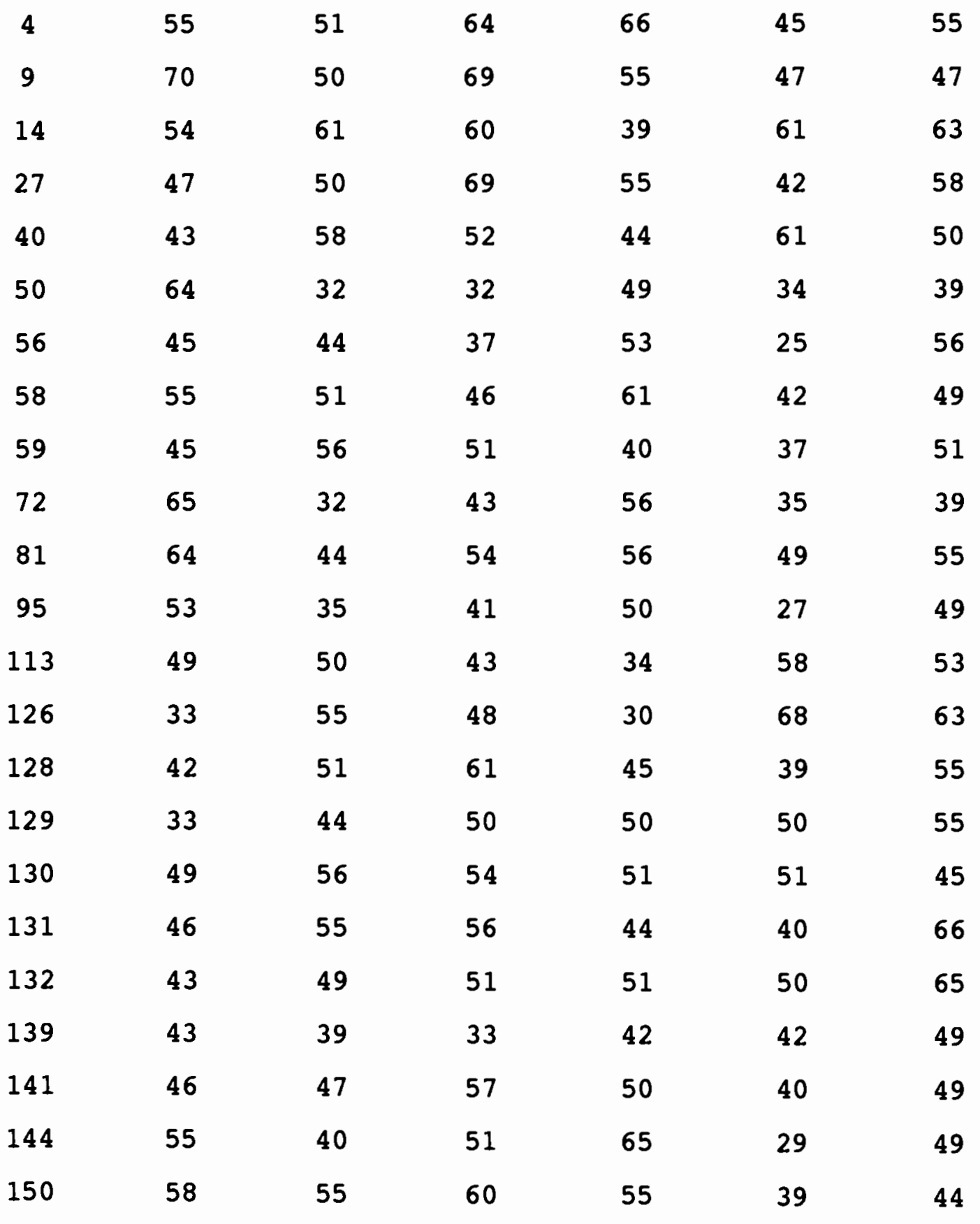


T-SCORES FROM TABC

HISTORY OF EXPRESSIVE LANGUAGE DELAY (HELD) SUBJECTS

Parent Forms

TEMPERAMENT VARIABLES

Subject\# Act

Adap Appr/with Emot

EMTD

Pers

$\begin{array}{lllllll}6 & 64 & 42 & 36 & 53 & 53 & 32 \\ 7 & 54 & 50 & 60 & 53 & 27 & 58 \\ 12 & 47 & 53 & 54 & 50 & 44 & 60 \\ 19 & 64 & 37 & 20 & 58 & 32 & 45 \\ 39 & 46 & 42 & 41 & 53 & 45 & 50 \\ 41 & 50 & 60 & 60 & 32 & 55 & 56 \\ 57 & 50 & 32 & 37 & 51 & 35 & 44 \\ 84 & 39 & 39 & 44 & 35 & 60 & 49 \\ 86 & 43 & 61 & 64 & 47 & 44 & 45 \\ 87 & 47 & 30 & 51 & 70 & 27 & 47 \\ 92 & 51 & 45 & 36 & 51 & 47 & 50 \\ 97 & 46 & 56 & 51 & 49 & 47 & 47 \\ 98 & 39 & 50 & 43 & 66 & 39 & 66 \\ 101 & 39 & 55 & 44 & 39 & 50 & 58 \\ 102 & 70 & 45 & 56 & 50 & 49 & 45 \\ 105 & 39 & 40 & 43 & 61 & 45 & 58 \\ 107 & 39 & 56 & 50 & 35 & 56 & 45 \\ 109 & 58 & 27 & 44 & 74 & 25 & 47 \\ 114 & 40 & 60 & 53 & 47 & 51 & 40 \\ 119 & 63 & 53 & 52 & 51 & 53\end{array}$




$$
\begin{gathered}
\text { T-SCORES FROM TABC } \\
\text { EXPRESSIVE LANGUAGE DELAY (ELD) SUBJECTS } \\
\text { Parent Forms }
\end{gathered}
$$

TEMPERAMENT VARIABLES

Subject\# Act

$\begin{array}{rll}15 & 45 & 40 \\ 29 & 61 & 42 \\ 93 & 37 & 60 \\ 94 & 54 & 49 \\ 100 & 46 & 39 \\ 111 & 70 & 20\end{array}$

42

63

45

37

55

56
EMTD

Pers

40

35

58

42

53

40 
T-SCORES FROM TABC

NORMAL IANGUAGE (NL) SUBJECTS

Clinician Forms

TEMPERAMENT VARIABLES

Subject\# Act

Adap Appr/With

Dist

Pers

$\begin{array}{cccccc}4 & 47 & 51 & 53 & 50 & 52 \\ 9 & 65 & 30 & 46 & 75 & 43 \\ 14 & 42 & 55 & 47 & 45 & 57 \\ 27 & 70 & 45 & 63 & 58 & 51 \\ 40 & 47 & 45 & 43 & 50 & 51 \\ 50 & 42 & 53 & 51 & 45 & 57 \\ 56 & 42 & 53 & 47 & 47 & 56 \\ 58 & 42 & 53 & 50 & 47 & 57 \\ 59 & 40 & 55 & 53 & 47 & 57 \\ 72 & 45 & 47 & 39 & 51 & 52 \\ 81 & 61 & 49 & 57 & 56 & 54 \\ 95 & 51 & 51 & 47 & 60 & 46 \\ 113 & 44 & 55 & 51 & 45 & 57 \\ 126 & 40 & 58 & 55 & 39 & 54 \\ 128 & 49 & 53 & 55 & 37 & 65 \\ 129 & 55 & 40 & 51 & 58 & 51 \\ 130 & 45 & 55 & 53 & 49 & 59 \\ 131 & 53 & 53 & 47 & 47 & 60 \\ 132 & 51 & 49 & 53 & 61 & 51 \\ 139 & 50 & 55 & 49 & 45 & 61 \\ 141 & 50 & 55 & 53 & 47 & 57 \\ 144 & 47 & 53 & 53 & 61 & 49 \\ 150 & 58 & 45 & 53 & 61 & 51\end{array}$


T-SCORES FROM TABC

HISTORY OF EXPRESSIVE LANGUAGE DELAY (HELD) SUBJECTS Clinician Forms

TEMPERAMENT VARIABLES

Subject\# Act

$6 \quad 51$

7

12

19

39

41

57

84

86

87

92

97

98

101

102

105

107

109

114

119

122

142
55

51

45

65

45

42

40

66

65

42

50

37

53

63

40

44

51

47

40

45

45
Adap Appr/With

42

32

51

45

30

56

50

53

49

35

55

34

61

49

30

50

51

45

49

53

55

51
50

51

45

32

45

53

45

43

53

46

51

39

45

50

50

49

46

46

50

50

49

37
Dist

Pers

51

49

49

55

48

60

55

57

54

43

60

43

65

54

43

61

59

55

54

55

50

55

47

56

45

59 


$$
\begin{gathered}
\text { T-SCORES FROM TABC } \\
\text { EXPRESSIVE LANGUAGE DELAY (ELD) SUBJECTS } \\
\text { Clinician FOrms }
\end{gathered}
$$

TEMPERAMENT VARIABLES

\begin{tabular}{cccccc} 
Subject\# & Act & Adap & Appr/with & Dist & Pers \\
\hline 15 & 50 & 55 & 58 & 50 & 49 \\
29 & 51 & 53 & 51 & 53 & 55 \\
93 & 53 & 50 & 45 & 49 & 54 \\
94 & 39 & 55 & 42 & 45 & 59 \\
100 & 42 & 55 & 45 & 49 & 59 \\
111 & 53 & 47 & 46 & 53 & 54
\end{tabular}

